\title{
Adherence to Antiretroviral Therapy in Adults: A Guide for Trainers
}

Horizons Program

International Centre for Reproductive Health

Mombasa Coast Province General Hospital

Follow this and additional works at: https://knowledgecommons.popcouncil.org/departments_sbsr-hiv

Part of the Family, Life Course, and Society Commons, Gender and Sexuality Commons, International Public Health Commons, and the Medicine and Health Commons

How does access to this work benefit you? Let us know!

\section{Recommended Citation}

Horizons Program, International Centre for Reproductive Health, and Mombasa Coast Province General Hospital. 2004. "Adherence to Antiretroviral Therapy in Adults: A Guide for Trainers." Nairobi: Population Council. 


\section{ADHERENCE 10}

\section{ANTIRETROVIRAL THERAPY}

\section{IN ADULTS}

\section{A Guide for Trainers}

Horizons/Population Council International Centre for Reproductive Health Coast Province General Hospital, Mombasa 
ADHERENCE TO ANTIRETROVIRAL THERAPY IN ADULTS A Guide for Trainers 


\section{ADHERENCE TO ANTIRETROVIRAL THERAPY IN ADULTS}

A Guide for Trainers

Horizons/Population Council International Centre for Reproductive Health Coast Province General Hospital, Mombasa (Ministry of Health, Kenya)

(1) Population Counal Hgrizons
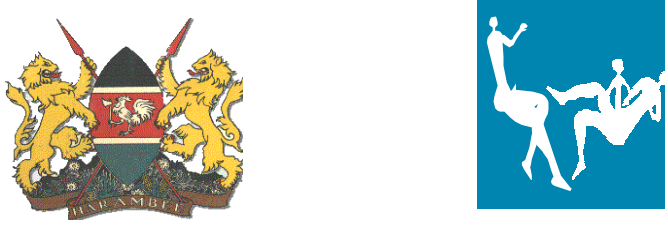
Population Council

Horizons Program

General Accident House

PO Box 17643-00500

Nairobi, Kenya

Tel: (254-20) 2713480

Fax: (254-20) 2713479

Email: pcnairobi@popcouncil.org

Website: www.popcouncil.org/horizons

(C) 2004, Population Council

ISBN 81-7525-520-X

This training manual was developed for the Antiretroviral Therapy Program in Mombasa, Kenya. The manual has been developed by the Horizons Program of the Population Council, the International Centre for Reproductive Health and the Coast Province General Hospital, Mombasa.

This study was supported by the Horizons Program, which is implemented by the Population Council in collaboration with the International Center for Research on Women, International HIV/AIDS Alliance, Program for Appropriate Technology in Health, Tulane University, Family Health International and Johns Hopkins University. Horizons is funded by the US Agency for International Development, under the terms of HRN-A-00-97-00012-00. The opinions expressed herein are those of the authors and do not necessarily reflect the views of the US Agency for International Development.

The Population Council is an international, non-profit, non-governmental institution that seeks to improve the well-being and reproductive health of current and future generations around the world and to help achieve a humane, equitable, and sustainable balance between people and resources. The Council conducts biomedical, social science and public health research and helps build research capacities in developing countries. Established in 1952, the Council is governed by an international board of trustees. Its New York headquarters supports a global network of regional and country offices.

This document may be reproduced in whole or in part without permission of the Population Council provided full source citation is given and the reproduction is not for commercial purposes.

Suggested citation: Horizons/Population Council, International Centre for Reproductive Health and Coast Province General Hospital, Mombasa-Kenya, 2004. Adherence to Antiretroviral Therapy in Adults: A Guide for Trainers. Nairobi: Population Council.

Printed in India by Mosaic Books. 


\section{Mombasa ART Project}

\section{Partners:}

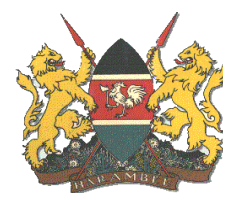

(2) Population Council

Hgrizons

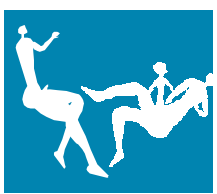

$\overparen{\mathrm{MSH}}$

Management Sciences for Health RPMPlus Rational Pharmaceutical Manage-

ment

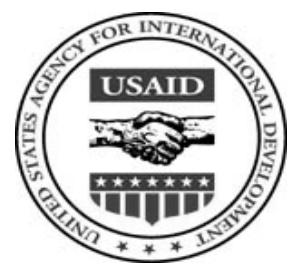

Ministry of Health, Government of Kenya

Coast Province General Hospital

Population Council, Horizons Program

International Centre for Reproductive Health

Family Health International

Management Sciences for Health

Rational Pharmaceutical Management Plus

United States Agency for International

Development (USAID) 


\section{Acknowledgements}

The Antiretroviral Therapy Program Mombasa, Kenya would like to acknowledge the following people and institutions for the invaluable contributions they have made to this training guide.

Dr Avina Sarna, Dr Samuel Kalibala, and Ms Susan Kaai from the Population Council Horizons Program and Dr Mark Hawken from ICRH wrote, reviewed and rewrote the various modules.

Dr Johannes van Dam of the Population Council Horizons Program provided support in Washington DC. Ms Leine Stuart, Senior Technical Officer Clinical Care and Dr John Adungosi, Project Coordinator from Family Health International and Ms Helena Walkowiak, Senior Program Associate, Centre for Pharmaceutical Management from Management Sciences Health Rational Pharmaceutical Management Plus provided important inputs to the document. Dr Khadija Shikely, Dr David Mwangi, Dr William Mbaya, Dr Kishor Mandaliya, Dr Vinesh Vaghela, Dr Mufidah Shabiby and Dr Francis Otieno from the Coast Province General Hospital reviewed the document and provided critical inputs.

We are grateful to the management and staff of the Coast Province General Hospital for supporting the whole process of developing these materials. We would like to acknowledge the contribution of our team of dedicated Adherence Nurse Counselors at Coast Province General Hospital: Sisters Ann Mwangemi, Mary Namuyu, Mariam Amran and Margaret Magina. We would also like to acknowledge Dr Caroline Olwande and Dr Lawrence Nzumbu from the pharmacy for their support on this project. We would like to acknowledge the contribution and support from the ICRH research team Mr Paul Munyao, Mr Gerald Kimondo, Ms Rebecca Isemele, Mr Jerry Okal, Ms Lilian Mutunga, Mr Nicodemus Kisengese and Ms Jacinta Mutegi. 


\section{List of Abbreviations}

$\begin{array}{ll}3 \text { TC } & \text { Lamivudine } \\ \text { ART } & \text { Antiretroviral Therapy } \\ \text { AZT } & \text { Zidovudine } \\ \text { Bomu Clinic } & \text { NGO Clinic } \\ \text { CHW } & \text { Community Health Worker } \\ \text { CCC } & \text { Comprehensive Care Clinic } \\ \text { CNS } & \text { Central Nervous System } \\ \text { CPGH } & \text { Coast Province General Hospital } \\ \text { d4T } & \text { Zerit, Stavudine } \\ \text { DAART } & \text { Directly Administered Anti-Retroviral Therapy } \\ \text { DDI } & \text { Didanosine } \\ \text { DOTS } & \text { Directly Observed Therapy-short course } \\ \text { EFV } & \text { Efavirenz } \\ \text { FBO } & \text { Faith Based Organization } \\ \text { HAART } & \text { Highly Active Anti-Retroviral Therapy } \\ \text { HW } & \text { Health Worker } \\ \text { MEMS } & \text { Medication Events Monitoring System } \\ \text { NVP } & \text { Nevirapine } \\ \text { PRDH } & \text { Port Reitz District Hospital } \\ \text { TB DOTS } & \text { TB Directly Observed Therapy—short course }\end{array}$




\section{Contents}

Acknowledgements vii

List of Abbreviations viii

Introduction $\quad$ xi

MODULE 1: Basic Information on Adherence 1

Activity 1: Brainstorming 4

Activity 2: Presentation 5

Activity 3: Group Work 13

Activity 4: Review 13

Additional Reading Material 14

1. HIV Infection and Antiretroviral Treatment 14

1.1 What are the Challenges of Taking HAART? 14

1.2 What is the Goal of HAART Therapy? 15

1.3 Viral Resistance 15

2. What is Adherence? 16

2.1 How much Adherence is required for optimal results? 16

2.2 How common is Non-Adherence? 17

2.3 How does Adherence to HAART compare with Adherence to other medications? 17

2.4 What are the forms of Non-Adherence? 17

2.5 What are the consequences of Non-Adherence? 18

2.6 What are the factors that Influence Adherence? 18

2.7 How Can Adherence be Assessed and Monitored? 20

2.8 Strategies and Tools to Enhance Adherence 22

MODULE 2: Patient Preparation for Adherence

Activity 1: Brainstorming 28

Activity 2: Presentation and Discussion 30

Activity 3: Review: Q \& A 37

Additional Reading Material 38

1. Patient Assessment 38

2. Patient Preparation for Treatment 38

2.1 Establishing Trust Between Patient and Provider 39

2.2 Introduction to the Treatment and Adherence Program 39 
2.3 Assessing the patient's health status 40

2.4 What Patients Can Expect to See with Treatment 43

2.5 The Importance of Adherence 44

2.6 Prior Use of Antiretrovirals 44

2.7 Patient's Beliefs and Attitudes 44

2.8 Social Support and Socio-Economic Situation 44

2.9 Establishing a Treatment Plan 45

2.10 Discussing the Proposed Adherence Strategy 46

3. Identifying Barriers to Adherence 46

4. Number of Preparatory Visits 51

5. The Multidisciplinary Adherence Team 51

5.1 Role of the Physician 52

5.2 Role of the Nurse Counselor/Nurse Case Manager 52

5.3 Role of the Pharmacist 52

\section{MODULE 3: Preparatory Adherence Counseling}

Activity 1: Brainstorming 56

Activity 2: Presentation 57

Activity 3: Group Activity: Case Studies 63

Activity 4: Review 68

Additional Reading Material 69

1. Adherence Counseling: Its Nature and Purpose 69

1.1 Attributes of a Good Adherence Counselor 70

1.2 Effective Counseling Techniques 70

2. Pre-treatment Adherence Counseling 72

2.1 Preparatory Counseling Session 1: Preparing the ground for adherence 73

2.2 Preparatory Counseling Session 2: Continued Treatment and Adherence Counseling 80

2.3 Preparatory Session 3: Assessment of Patient Readiness and Initiation of ART 83

MODULE 4: Ongoing Adherence Counseling

Activity 1: Presentation and Discussion 87

Activity 2: Group Activity: Role Play 98

Activity 3: Review. Q \& A 100

Additional Reading Material 101

1. Follow-up Counseling and Ongoing Support 101

1.1 Follow-Up Counseling Session 101

1.2 Ongoing Support 104

Information Resources 


\section{Introduction}

\section{HAART AND CHALLENGES OF HAART}

Over the last 5 years, there has been a rapid change in treatment strategies for HIV infection. With the advent of newer antiretrovirals, treatment has moved from mono-therapy and bi-therapy to triple drug therapy or Highly Active Antiretroviral Therapy (HAART). Treatment with a cocktail of three or more antiretroviral medications is now standard treatment protocol.

One of the foremost concerns of ARV programs is the ability of people living with HIV/AIDS (PLHA) to maintain near perfect adherence over the long term. In order to achieve the goal of antiretroviral therapy (ART), undetectable levels of the virus in the blood, patients are required to maintain more than $90-95 \%$ adherence.

Adherence is defined as a patient's ability to follow a treatment plan, take medications at prescribed times and frequencies, and follow restrictions regarding food and other medications. Both patients and health care providers face significant challenges with respect to adherence to ART. Once initiated, HAART is a life-long treatment that consists of multiple medications to be taken two to three times a day with varying dietary instructions. These medications also have side effects, some of which may be temporary while others may be more permanent requiring a change of treatment. Inadequate adherence to treatment is associated with detectable viral loads, declining CD4 counts, disease progression, episodes of opportunistic infections and poorer health outcomes.

ARV programs are being initiated in several developing countries. The Mombasa ART project was initiated in 2003 and was designed to serve as a learning site for other programs starting up ART service delivery in public health facilities in Kenya as well as other countries.

This Adherence Training Manual was developed using best practices from the New York State Medical Services, experiences from the Whitman Walkman Clinic in Washington DC and the INOVA Juniper program in 
Virginia, training programs from the University of Florida and the WHO VCT Counseling Manual for Asia. The manual has been developed in close collaboration with implementing partners keeping in mind the field reality and cultural environment of Mombasa, a coastal province in Kenya.

The Adherence Training Manual has been designed for health workers including physicians, clinical officers and adherence nurse counselors in ARV programs. The manual consists of four modules to be conducted over four sessions of approximately 2 hours each. These sessions can be conducted as a part of a comprehensive ART training program. The manual is designed for health workers and adherence counselors who have received some training on ARV medications. In Mombasa, adherence training was introduced on Day Two of a 5-day comprehensive ART training with a module covered each day on days 2, 3, 4 and 5 .

Module 1 provides a background on adherence to ART and is relevant for all health workers involved in ART service delivery. Modules 2, 3 and 4 provide detailed adherence management of a patient on ART designed for adherence nurse counselors. Physicians would benefit from attending the session on Module 2. The objective for each session is given at the beginning. The methodology, the materials required, the expected duration and the handouts are given in the margin at the beginning of each exercise. Handouts for the training use actual patient literacy materials (FHI/IMPACT 2003), counseling checklists, pill charts and medication demonstration charts being used in the Mombasa ART program.

\section{CONDUCTING AN EFFECTIVE TRAINING PROGRAM}

The ideal number of participants would be 15-20. Ideally a team of two trainers should conduct the program. A certain amount of advance preparation is required. Trainers need to prepare by going through the additional reading material and planning the sessions. It may be useful to have two of the participants sum up the lessons from the previous session (previous day) at the beginning of each day. Encouraging interactive sessions with discussion will make the program more effective.

The manual uses different techniques in this module: brainstorming, small group discussion, Power Point presentation, case studies and role-play. Brainstorming, small group discussions and interactive sessions provide an opportunity for a large number of participants to share their views. Power Point presentations are useful in providing participants with the theory and 
background on the topics being discussed. Case studies help participants discuss and understand the issues in a practical way. Role-play provides practical training in developing adherence-counseling skills.

The manual was tested and used to train health workers and adherence nurse counselors at Coast Province General Hospital and staff at the scale-up sites: Port Reitz District Hospital, BOMU clinic and Magongo health centre. The manual has also been adapted by NASCOP, Kenya.

This manual is one of the first adherence counseling training tools developed in Africa. As the ART program grows and patients have been on ART for a longer period, new patient management issues and challenges regarding adherence to treatment in the long-term will emerge. The manual will undergo revision and updating. We look forward to learning about your experiences and feedback on this training manual. Your suggestions and feedback will be extremely useful in improving and updating the manual.

For additional information or sending feedback/suggestions, contact Avina Sarna at asarna@pcindia.org. 


\section{MODULE 1 \\ Basic Information on \\ Adherence}



MODULE 1

\section{Basic Information on Adherence}

\section{OBJECTIVE}

To provide trainees with a basic understanding of the challenges of HAART and adherence to antiretroviral therapy

\section{ACTIVITIES}

1. Brainstorming: Discussion on adherence and challenges of HAART.

$30 \mathrm{~min}$.

2. Presentation: Goals of therapy, levels of adherence required, consequences of non-adherence, methods to monitor adherence and strategies and tools to enhance adherence.

$45 \mathrm{~min}$.

3. Group activity: Discuss strategies to promote adherence. $30 \mathrm{~min}$.
4. Review. $15 \mathrm{~min}$.

Total $2 \mathrm{~h}$

\section{HANDOUTS}

- Additional reading material on Module 1: 'Adherence to Antiretroviral Therapy'

- Power point presentation for Session 1 


\section{Activity 1: Brainstorming}

This activity is designed to prepare trainees to understand the challenges of adherence to HAART therapy. Most trainees will have already participated in the general training on HIV/AIDS and antiretroviral therapy in the hospital. The trainer will build on earlier knowledge and lead the trainees through an initial brainstorming exercise, where information about HAART and adherence is discussed using lead questions. The trainer will draw on experiences with adherence to TB treatment and treatment of other chronic

METHODOLOGY: Large group interaction

MATERIALS:

Flip charts

DURATION $30 \mathrm{~min}$. diseases in the hospital. Discussion will include challenges of HAART and factors that influence adherence. It will be based on the reading material provided so that trainees recall the issues discussed when reading the material later. 


\section{Activity 2: Presentation}

METHODOLOGY:

Power Point

presentation

HANDOUT:

Copies of presentation

DURATION 45 min.

The presentation will discuss the theory and more technical issues around adherence: the goals of therapy, levels of adherence required, consequences of non-adherence and methods to monitor adherence. The presentation will cover issues presented in the additional reading material so that trainees recall the issues presented when reading the material later.

\section{Enhancing Adherence to HAART}

(1) Pouldinincunal
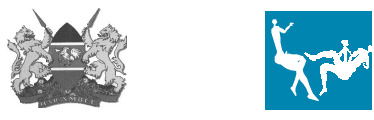

Hgrizons

\section{Training Objectives}

At the end of this session the participants should have a basic understanding of:

$>$ Challenges of adherence to HAART

$>$ How adherence can be monitored

$>$ How adherence can be enhanced 


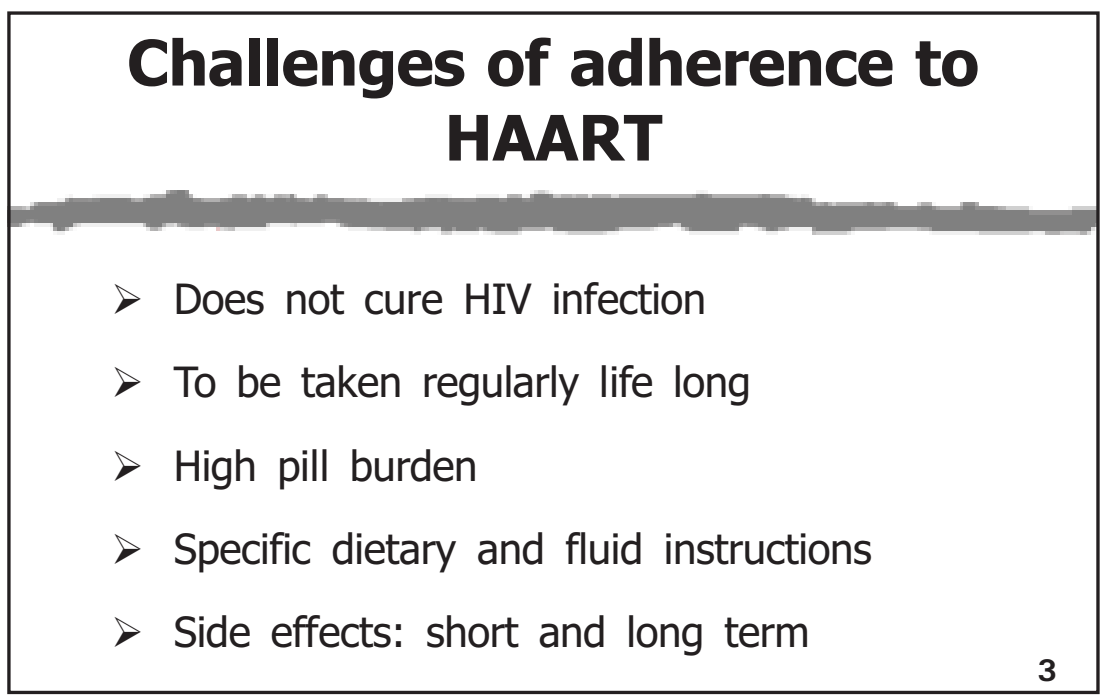

\section{Adherence vs. Compliance}

Adherence: the act or quality of sticking to something, steady devotion; the act of adhering

$>$ Acceptance of an active role in one's own health care

Compliance: the act of conforming, yielding or acquiescing

$>$ Lack of sharing in the decision made between provider and client

\section{How much adherence is required for successful therapy?}

$>$ Goal of HAART = maximal and durable viral suppression (undetectable levels)

> Successful HIV therapy requires adherence > 95\%

> Failure rates increase sharply as adherence decreases 


\section{Adherence to ART and Virological failure rates (Patterson et al 2000)}

\section{Adherence and virological failure rates}

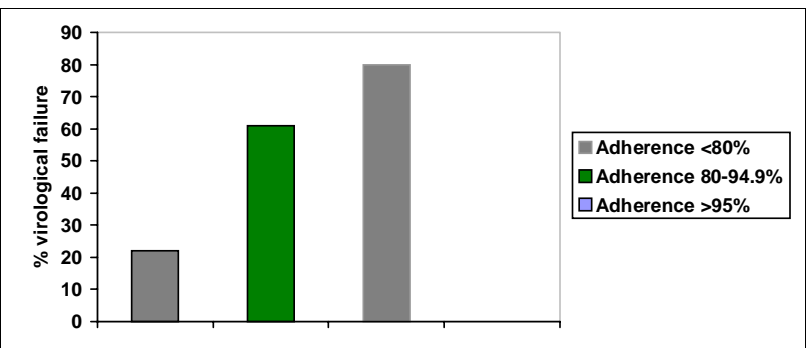

\section{Consequences of poor adherence}

Incomplete viral suppression

$>$ Continued destruction of the immune system - CD4 cell counts

$>$ Disease progression

$>$ Emergence of resistant viral strains

> Limited future treatment options

Higher costs to the individual and ARV program

\section{Forms of non-adherence}

Missing one dose of a given drug

> Missing multiple doses of one or more prescribed medications

> Missing whole days of treatment

> Not observing the intervals between doses

$>$ Not observing the dietary instructions 


\section{How common is non-adherence?}

$>$ More than $10 \%$ of patients report missing one or more doses on any given day

$>$ More than 33\% report missing doses in past 2-4 weeks

> Providers cannot easily accurately guess whether a given patient will be adherent or not

\section{Factors influencing adherence}

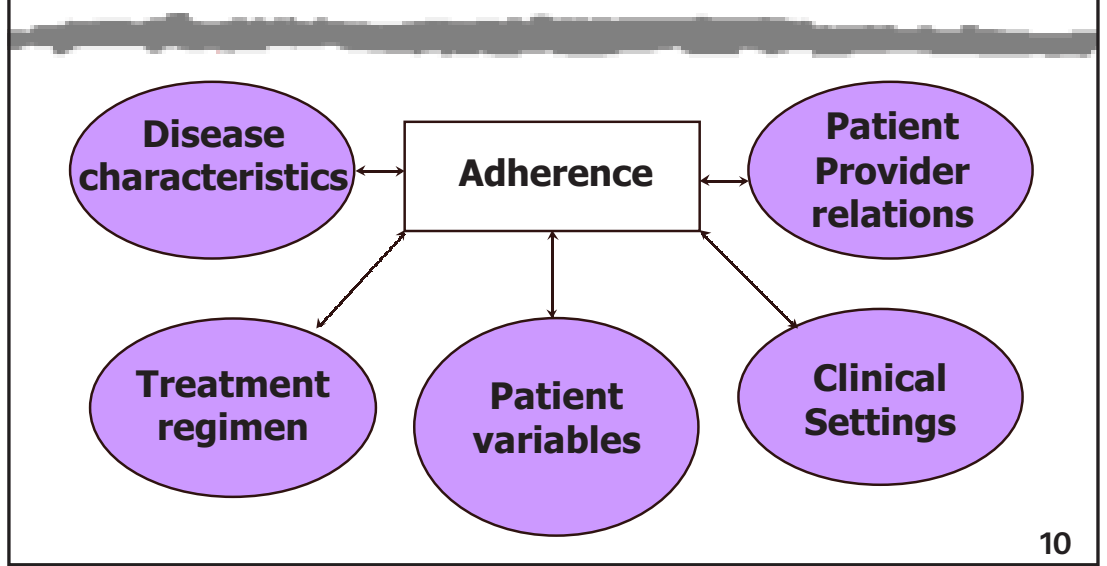

\section{Measuring adherence (Summary of methods)}

$>$ Self reports

$>$ Pill counts

$>$ Pharmacy records

$>$ Biological markers

$>$ Electronic devices

$>$ Measuring drug levels 


\section{Self Report}

Various periods of recall $-1,3,4,7,30$ days

Self-report agrees well with actual medication intake and viral load

Tends to overestimate

Easiest to do in a clinic setting

\section{Self Report}

Accuracy of self-report can be maximized by:

Approaching the client in a matter of fact and non-judgmental way!

Asking about the most recent days

Asking about missed doses

Using prompts to help recall

\section{Pill Counts}

> Providers count remaining pills during clinic visit

$>$ Problems

$>$ Patients can dump pills prior to visit

$>$ Promotes a sense of distrust between patient and provider

Unannounced pill counts

$>$ Done at home

$>$ Can be more reliable

$>$ Feasibility? 


\section{Pharmacy Records}

Pharmacists keep record of medications dispensed to patients

Can inform the doctor about lapses in patients refilling prescriptions

> Problems:

$>$ This is not a measure of ingestion of medications

$>$ Requires patients to always use the same pharmacy

\section{Biological markers of effectiveness of treatment}

Decreasing viral load implies good adherence

In some patients viral load may remain high even with good adherence

$>$ Viral resistance

$>$ Treatment failure

$>$ Poor absorption of drug

\section{Others}

> Electronic devices - MEMS

$>$ Measures opening of bottles

$>$ Allows for multiple measures

$>$ Correlates well with viral load outcomes

$>$ Expensive

$>$ Training needed

$>$ Measuring drug levels

$>$ Expensive

$>$ Drug levels in blood have short circulating times 


\section{Enhancing adherence (summary of methods)}

Counseling

> Medication diaries

$>$ Pill boxes

$>$ Buddy system (peer, friend, family)

$>$ Modified DOT/DAART

$>$ Incentives (food, transport, etc.)

> Electronic devices (pagers, alarms, beepers, etc.)

\section{Adherence counseling}

\section{Knowledge}

$>$ HIV disease, CD4 counts

$>$ Medications and side effects

\section{Attitudes}

> Positive belief and perceptions

$>$ Self efficacy and commitment

> Practices and support systems

$>$ Disclosure, buddies, family support

Identifying and addressing barriers

Integrating treatment regimen into patient's daily routine

Encourage family involvement

Providing reminder cues

\section{Adherence is a dynamic process}

Levels change over time

$>$ Influenced by multiple factors, no factor stands alone

Requires a combination of promotion strategies

Requires an integrated multidisciplinary team effort 


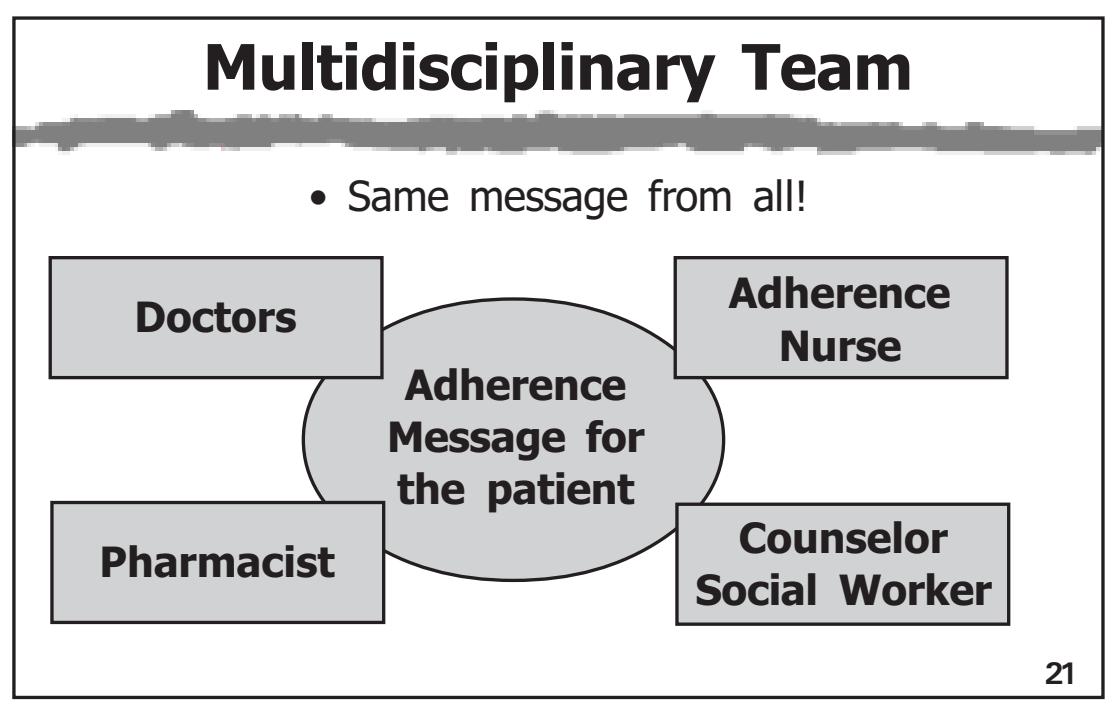




\section{Activity 3: Group Work}

METHODOLOGY:

Small group discussion

MATERIALS:

Flip chart

DURATION $30 \mathrm{~min}$.

\section{METHODOLOGY:}

Volunteer Discussion

\section{MATERIALS:}

Flip Chart, Additional Reading Material

DURATION $15 \mathrm{~min}$.
Discuss strategies to promote adherence. Divide into three groups. Groups will be provided a list of strategies to discuss - write list on flip chart. Each group will discuss the pros and cons of each of the listed strategies. The groups will also list practical strategies for their program and patients. Each group presents key points of discussion at the end of the session.

\section{List of Strategies to Discuss}
a. Counselling
b. Pillboxes
c. Electronic devices
d. Telephone reminders
e. Medication diaries
f. 'Buddy' system
g. Pill charts
h. Directly Observed Therapy (DOT)
i. Incentives

\section{Activity 4: Review}

Review discussion of the day. Provide additional reading material. Ask two volunteers to sum up the main points for the day. Allow trainees to ask questions, seek clarifications or additional information. Encourage trainees to read material and discuss issues the next morning prior to next training session. 


\section{ADDITIONAL READING MATERIAL}

\section{Adherence to Antiretroviral Therapy}

\section{HIV INFECTION AND ANTIRETROVIRAL TREATMENT}

Over the last five years, there has been a rapid change in treatment strategies for HIV infection. With the availability of newer antiretrovirals, treatment has moved from mono-therapy and bi-therapy to triple drug therapy or Highly Active Antiretroviral Therapy (HAART). Treatment with a cocktail of three (or more) antiretroviral medications is now standard treatment protocol.

\subsection{What are the Challenges of Taking HAART?}

HAART consists of three or more antiretroviral medications to be taken in combination. In addition to antiretroviral medications, patients also have to take medications for treatment or prevention of opportunistic infections. All these medications can add up to 16 to 20 pills a day with multiple dosing throughout the day, especially with protease inhibitor containing regimens. The enormous pill burden is a major challenge.

In addition some antiretroviral medications also require specific food and fluid restrictions. For example, patients would need to take Crixivan or Indinavir 1 hour before or 2 hours after meals and patients should drink at least 1.5 litres of water or fluids daily to prevent formation of kidney stones.

Furthermore, HAART can often lead to adverse events that may be temporary such as nausea, vomiting, diarrhea, fatigue etc., or longer lasting such as neuropathy, lipoatrophy/lipodystrophy, metabolic dysfunction etc. Side effects have been seen to be a major reason for patients discontinuing their medications.

Antiretroviral medications control HIV virus replication or multiplication. Even when the virus becomes undetectable in the blood with successful ART, there are some sites in the body where drugs are unable to reach the virus. These sites are called sanctuary sites. Therefore the virus cannot be completely eradicated from the body and continues to remain hidden in these sanctuary sites. The virus emerges when ART fails or is stopped. As the

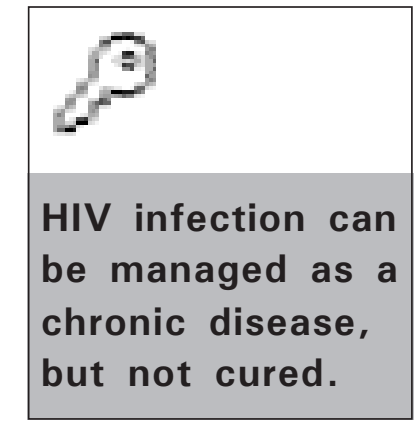


Goal of HAART:

Maximal +

durable

suppression of virus replication virus cannot be eradicated, antiretroviral medications have to be taken regularly, long-term, for the rest of the patient's life. HIV infection can therefore be managed but not cured.

\subsection{What is the Goal of HAART Therapy?}

The goal of HAART is to achieve maximal and durable suppression of virus replication. This in turn reduces the destruction of CD4 cells, reduces immune suppression and slows disease progression. Success with HAART can be seen in rising CD4 cell counts, undetectable viral loads and clinical improvement in patients receiving HAART. As viral load assays are expensive, in resource-limited settings, CD4 counts and clinical physical examination become the main tools for monitoring treatment outcomes.

\subsection{Viral Resistance}

When patients take their medications irregularly or when providers prescribe inappropriate doses or combinations of medications the virus is exposed to inadequate (sub-inhibitory) concentrations of antiretroviral medications. This in turn leads to ongoing viral replication and to the development of resistance to antiretroviral medications. Resistance to antiretroviral medications accounts for a large portion of treatment failures.

The critical problem is the issue of 'cross-resistance'. Once the virus becomes resistant to a particular antiretroviral medication, the virus may also exhibit resistance to other medications of the same class that have not yet been prescribed to that patient. This limits the choice of drugs available to replace the failing regimen. For example, resistance to Nevirapine would mean that the patient cannot use other NNRTI medications such as Delavirdine (Rescriptor) or Efavirenz (Sustiva).

The second issue with viral resistance is that resistant strains of the virus can be transmitted. It has been seen that some patients diagnosed for the first time with HIV, who have never taken ARVs, are already resistant to some anti-retroviral medications. This is a major public health problem in resource-limited situations where the choice of medications is already restricted due to high costs and limited availability. It becomes all the more important for patients to take their medications regularly and correctly to avoid the emergence of resistance. 


\section{WHAT IS ADHERENCE?}

Adherence is defined as 'the act or quality of sticking to something - to adhere to something'. In the context of treatment with medications, adherence means a more collaborative process between the patient and provider. The patient plays a more active role in his treatment and makes a commitment to follow the prescribed regimen as best as possible.

How is it different from 'Compliance'? The dictionary defines compliance as 'the act of conforming, yielding or acquiescing' implying thereby a lack of patient participation.

\subsection{How much Adherence is required for optimal results?}

The goal of HAART (Highly Active Antiretroviral Therapy) is to suppress viral load in the blood to undetectable levels (levels that are no longer detectable in routine viral load assays). Adherence to treatment is critical to obtain full benefits of HAART: maximal and durable suppression of viral replication, reduced destruction of CD4 cells, prevention of viral resistance, promotion of immune reconstitution and slowed disease progression.

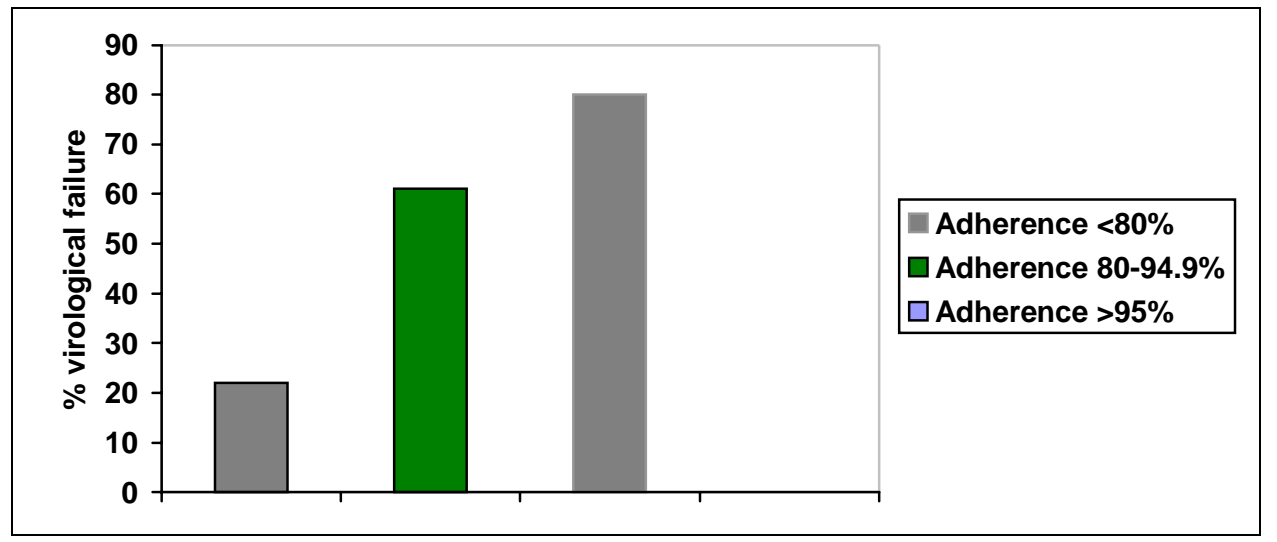

Fig. 1.1: Virological failure rates and adherence to ART (Patterson et al., 2000)

Paterson and colleagues found that adherence greater than $95 \%$ is needed to achieve virologic success, especially for protease inhibitor containing regimens.

As adherence decreased, viral loads increased sharply in a dose response effect. The study showed that $22 \%$ patients with adherence of greater than $95 \%, 61 \%$ of patients with adherence between $80-94.9 \%$ and $80 \%$ of patients 
with adherence levels of less than $80 \%$ demonstrated virological failure. Virological failure was defined as detectable viral loads (Paterson et al., 2000).

What does 95\% adherence translate into? For example Zerit (D4T) is taken twice a day. A patient should take 60 pills over one month (30 days). To achieve $95 \%$ adherence a patient must take at least 57 of his 60 tablets. Missing four pills or doses would result in $93 \%$ adherence and missing five pills would result in $91 \%$ adherence.

\subsection{How common is Non-Adherence?}

Unfortunately, non-adherence is common among individuals treated with HAART. Several studies have shown varying levels of adherence: more than $10 \%$ of patients report missing one or more medication doses on any given day, and more than $33 \%$ report missing doses in the past two to four weeks (Chesney et al., 2000). Chesney estimated that the average non-adherence to ARV therapy ranged from 50 to 70 percent among patients in the US.

Physicians and nurses cannot accurately guess whether a person will be adherent or non-adherent.

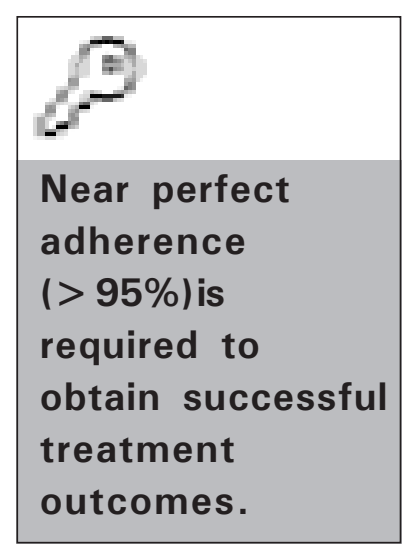

\subsection{How does Adherence to HAART compare with Adherence to other medications?}

Most information on adherence is coming from western countries. It is seen that the rates of non-adherence to HIV therapies are comparable to those for other chronic illnesses. In the case of chronic diseases such as hypertension or diabetes lower levels of adherence, around $70-80 \%$, are considered adequate to achieve treatment goals. In the case of ART, near perfect adherence (adherence levels greater than 95\%) is required to obtain a successful treatment outcome.

\subsection{What are the forms of Non-Adherence?}

Non-adherence can vary from missing one dose of a medication to missing a single dose of all three or four medications to missing multiple doses or all doses a day or week. Not observing instructions regarding dietary or fluid intake or not taking medications at prescribed time intervals also constitutes non-adherence. 


\subsection{What are the consequences of Non-Adherence?}

As has been mentioned earlier, very high levels of adherence (near perfect adherence) are required to achieve the full benefits of HAART. Non-adherence can lead to inadequate suppression of viral replication, continued destruction of CD4 cells, progressive decline in immune function and disease progression. Non-adherence is also an important reason for the emergence of viral resistance to one or more antiretroviral medications.

\subsection{What are the factors that Influence Adherence?}

Factors that influence adherence can be categorized to include: patient factors, treatment regimen, disease characteristics, patient-provider relationship and clinical setting (Fig. 2).

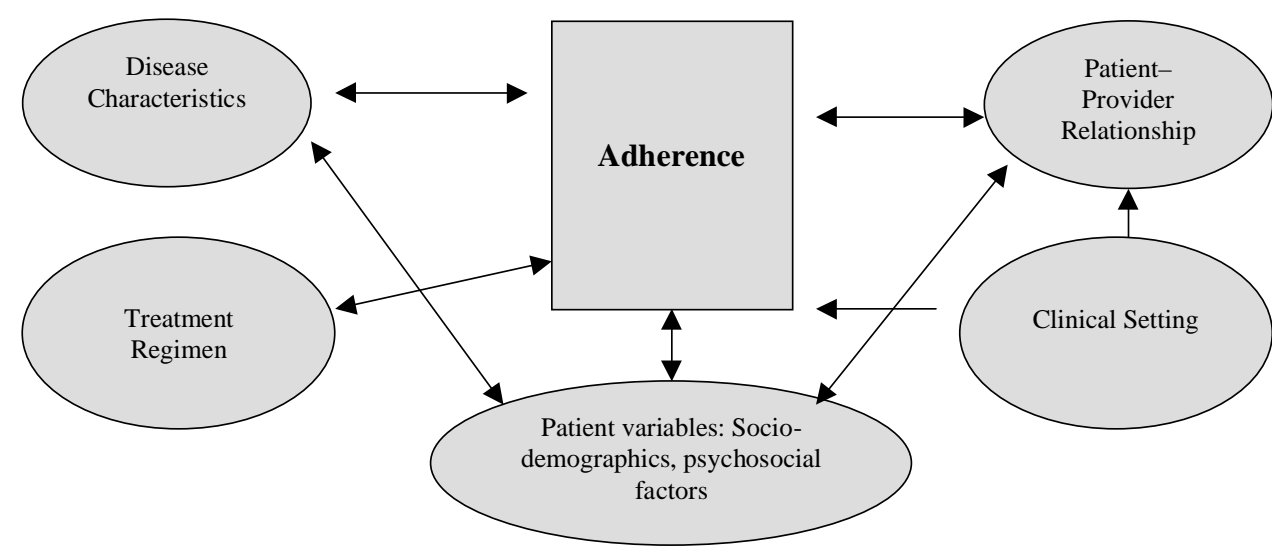

Fig. 1.2: Determinants of adherence (J R Ickovics \& C S Meade, AIDS Care, 2002)

\section{a. Patient factors}

Patient factors that have been studied include: socio-demographic factors, such as gender, ethnicity, age, employment, income, education and literacy; and psychosocial factors, such as active drug or alcohol use, degree of social support, social stability, depression and other psychiatric illnesses.

In general, socio-demographic factors do not seem to predict adherence behaviour, although some studies have found that male sex, white ethnicity, older age, higher income and higher education and literacy correlate with better adherence. On the other hand, a number of psychosocial factors have been found to strongly influence adherence. Depression, psychiatric illness 
and active alcohol or drug use prevent patients from adhering to treatment. Social support helps patients adhere better (Ickovics and Meade, 2002).

A patient's knowledge of his medication regimen and a patient's understanding of the relationship between non-adherence and build-up of resistance to medication also predict better adherence. A patient's belief and confidence in therapy and his/her self-efficacy (confidence in oneself to be able to adhere) also influence adherence to medication.

\section{b. Medication factors}

HAART consists of a complex regimen that can include up to 20 pills a day, with multiple dosing throughout the day and specific food and fluid related instructions. These are often difficult to follow for patients and contribute to poor adherence. The higher the pill burden, the lower is the adherence. Patients report taking 'drug holidays' as a result of 'pill fatigue'.

Antiretroviral medications often have side effects, some of which are temporary: diarrhea, fatigue, nausea and vomiting; while others may be permanent or longer lasting: peripheral neuropathy, physical changes in body appearance, lipoatrophy/lipodystrophy, metabolic changes. Studies have shown that when patients experience side-effects, they tend to stop treatment or take it irregularly.

\section{c. Patient-provider relationship}

The patient-provider relationship plays an important role in improving adherence to prescribed medications in chronic disease. It is believed to be a motivating factor for adherence to HAART. Trust and confidence in providers has been found to influence adherence positively (Altice et al., 2001).

\section{d. Disease characteristics}

Prior opportunistic infections (OI) contribute to increased adherence. Patients who have had serious opportunistic infections may perceive their illness to be severe and adhere better to their treatment (Singh et al., 1996).

\section{e. Clinical setting}

Although existing data is limited, aspects of the clinical setting may be associated with improved adherence. A friendly, supportive and nonjudgmental attitude of health care providers, convenient appointment scheduling and confidentiality contribute to better adherence. 


\subsection{How Can Adherence be Assessed and Monitored?}

Measuring adherence is problematic as there is no single method to assess adherence accurately. There is no 'Gold Standard'. Therefore, multiple approaches are used to assess adherence. Some of the currently used measures are client self report, electronic monitoring devices, pill counts, provider estimation and measurement of medications in the blood stream.

\section{a. Self-report}

Patients are asked to report their own adherence in a self-report. Different periods of recall may be used - four-day, one-week, one-month or most-recent recall of missing a dose. Although patients often tend to overestimate their adherence, several studies have found that the self-report correlates fairly well with actual medication intake when a trusting patient-provider relationship has been established. Self-report assessment can be obtained at the time of clinic visits, through a series of questions asked in a nonjudgmental manner. Accuracy of the self-report can be maximized by (i) approaching the patient in a matter of fact and non-judgmental way, (ii) asking about the most recent days and missed doses, and (iii) using prompts to help recall. The self-report is presently the easiest tool to use in a clinical setting.

\section{b. Electronic devices}

Medication Events Monitoring System (MEMS) consists of an electronic chip embedded in the lid of the medication bottle. The chip records the opening and closing of the bottle. A computer program downloads the information from the lid and gives a written report.
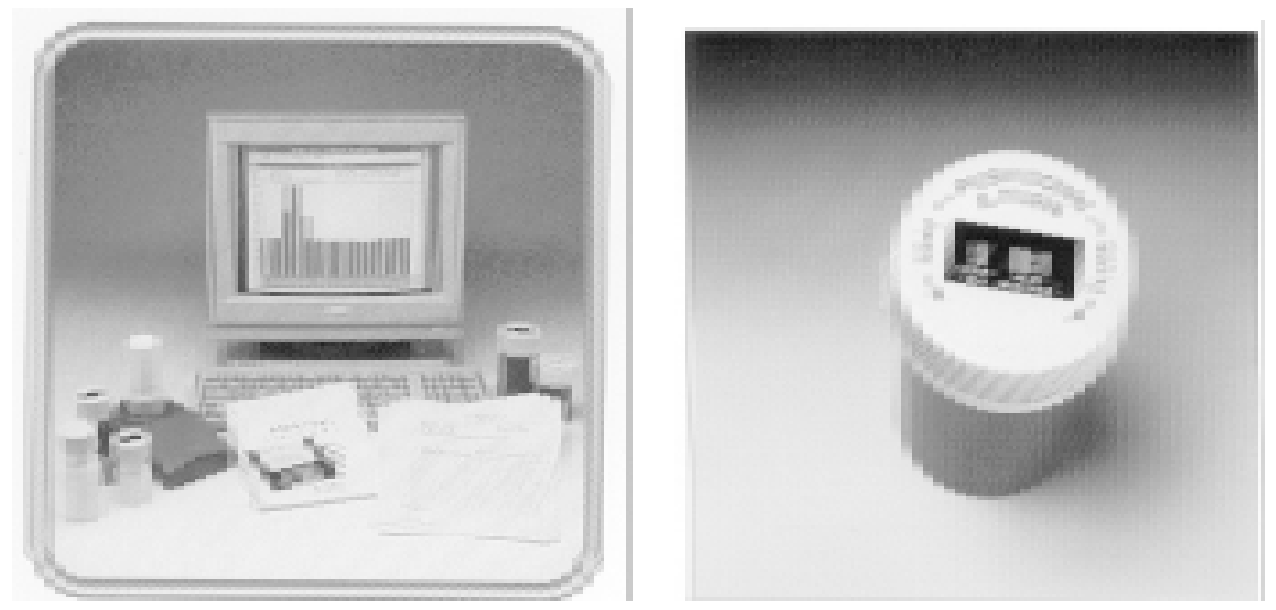

Fig. 1.3: Left: MEM System; Right: MEMS Bottle 
The Medication Events Monitoring System records the date and time of each opening of the cap and assumes that opening coincides with intake. Using MEMS allows multiple measures of adherence to be recorded: opening (intake), timing of opening, intervals between doses etc. Studies have found adherence measured using MEMS caps to correlate fairly well with medication intake. There are, however, some disadvantages associated with its use: (i) MEMS can underestimate intake as patients sometimes remove multiple doses at one time; (ii) both patients and providers require training in its use; (iii) MEMS fails to work if patients leave the cap off or lose the cap; (iv) it is very expensive-MEMS is often used to measure adherence for only one of the prescribed medications; and (v) the use of MEMS also precludes the use of pillboxes which patients often find useful.

\section{c. Pill counts}

Health care workers conduct pill counts during scheduled clinic visits. The main disadvantage of this method is that patients can manipulate pills. Pill dumping prior to scheduled visits leading to an overestimation of adherence. This method also relies on patients to bring their medication at the time of clinic visits.

Unannounced pill counts may be more accurate. However visiting patients' homes is resource-intensive and there may be issues of confidentiality and stigma in the community. Pill counting may also hinder the development of a trusting relationship between the patient and provider.

\section{d. Pharmacy refill tracking}

Pharmacists play a key role in supporting patient adherence to medication. Pharmacists educate the patient about their medication and conduct pill counts. They also inform providers about lapses in refills or problems the patient may be experiencing with taking medication. Pharmacy refill data has been used as an additional indicator of adherence. Patients collecting their medications regularly on due dates are assumed to be adhering to treatment. An effective record keeping system is essential for pharmacy refill data to be used. Some of the disadvantages with pharmacy refill tracking are that: (i) it is not a measure of intake of medication, and (ii) it requires patients to use the same pharmacy for all refills.

\section{e. Biological markers}

Since the goal of HAART therapy is to lower the plasma viral load, monitoring viral load can be used as an indicator of effectiveness of treatment, and thereby of medication intake. In some patients, however, viral loads may remain high even though patients take all their medications regularly. This could be 
due to problems of non-response due to viral resistance, treatment failure or poor absorption of the drug. Viral load monitoring is very expensive and may not be available in resource-constrained settings.

\section{f. Provider estimation}

Studies have found this measure to be the most poorly correlated with medication intake.

\section{g. Therapeutic drug monitoring (TDM)}

Measuring drug levels in blood is not being used to measure adherence due to short circulating times for most antiretroviral medications as well as the expense related to conducting therapeutic drug measurements. At the present time TDM is limited only to research settings.

\subsection{Strategies and Tools to Enhance Adherence}

Several different strategies have been used to enhance adherence singly or in combination.

\section{a. Counseling}

Counseling forms the mainstay of any treatment program. Counseling aims to improve patient knowledge about the disease and knowledge about the medications and side effects. Counseling helps the patient to set goals, to develop positive beliefs and perceptions and to increase self-efficacy. In addition to counseling, patients often need other forms of support to be able to adhere to treatment.

Adherence tools are helpful for many patients. Several different types of tools are in use, as listed below.

\section{b. Pillboxes}

Pillboxes are containers for storing medication with dividers for each day and each dose within the day. This makes it easy for patients to take doses correctly. Pillboxes with electronic reminders are also available. Some pharmacies in the west even distribute pre-loaded pillboxes. A possible disadvantage of the pillbox in developing country settings may be its visibility in situations where patients need to hide medications from others due to confidentiality reasons. Patients who are illiterate or very sick may need help to fill the pillboxes correctly. 


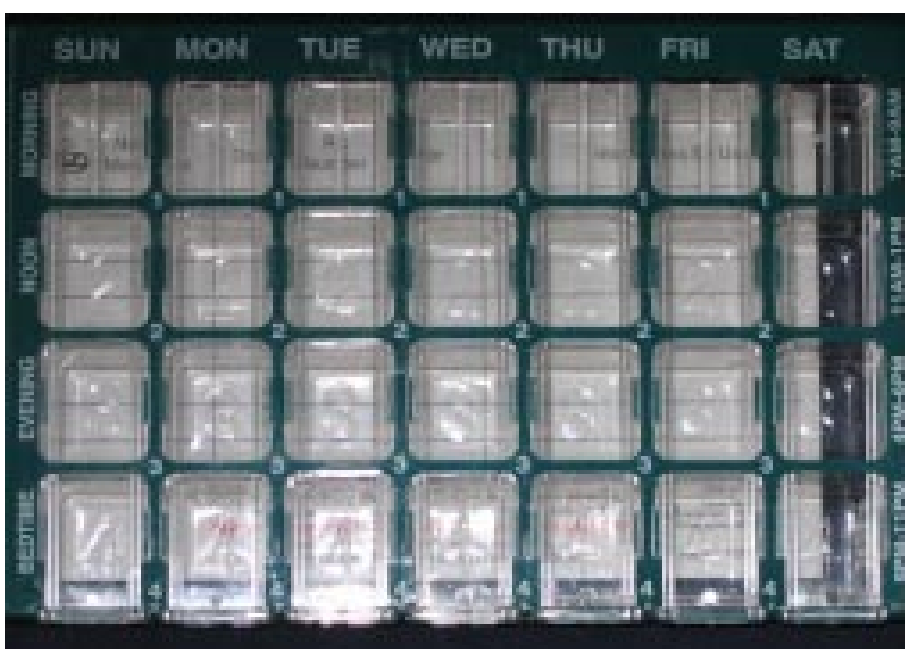

Fig. 1.4: Ezy Dose Pill Box (1 week, 4 daily doses)

\section{c. Electronic devices}

Many treatment programs in developed countries use electronic devices to enhance adherence to medications. Devices range from beepers to alarms to watches that remind patients to take medications on time. Electronic pagers that are linked to the internet are used to send messages to patients. Electronic devices need to be discreet to avoid stigma and confidentiality related issues. These tools may not be practical in developing country settings.

MEMS can be used both to measure adherence as well as a reminder tool for patients.

\section{d. Telephone reminders}

Telephone reminders are being tried out in some studies on adherence. There are several limitations to its use: it is labour intensive for staff, patients must have a telephone at all times and cost issues. Internet based confidential reminder services are also being used.

\section{e. Medication diaries}

These are diaries in which patients record the time and date of medication intake, missed doses and reasons for missed doses. These can serve as useful records of side effects or other problems patients may experience. This is a useful tool to identify patterns of use and reasons for missing doses.

\section{f. 'Buddy' system}

The Buddy system relies on a friend or family member to help the patient to take medications regularly-reminding the patient to take his medication on time, offering encouragement to keep going, helping to keep hospital appointments, providing support etc. 


\section{g. Pill charts}

Pill charts are used to visually display pills (colour and shape), names and dosage for each medication and are used by the nurse or health provider during counseling. This is a very useful tool for patients with literacy problems.

All the strategies, a to $g$, outlined above serve as 'enablers' for patients, helping patients organize their treatment taking.

\section{h. Directly Observed Therapy (DOT)}

DOT is an intensive program in which patients take their medication under the supervision of adherence staff. In TB DOTS programs health workers observe the intake of all medication doses for the entire treatment period of 6-9 months. TB DOTS is more regimented and provides a tighter monitoring of medication intake. In the case of ART, it is not practical to observe all doses as most HAART regimens have multiple doses and treatment is lifelong. Therefore, only some doses are observed for a fixed period of time (a few months). This is called modified DOT or directly administered antiretroviral therapy (DAART). Modified DOT can be done at health centres, in community-based organizations or even at a patient's home. In the management of HIV infection, a modified DOT strategy, through frequent patient-provider contact, is used as a behavioural intervention that helps patients (i) to develop an understanding of the treatment; (ii) to develop good treatment taking behaviour; (iii) to receive support during the first few weeks of antiretroviral therapy when patients have short term side-effects; and (iv) to develop a trusting relationship with providers.

\section{i. Incentives}

Several programs in the US are using incentives such as telephone cards, transport and food coupons, shopping coupons, movie tickets, tickets to sports events etc. to increase effectiveness of ART intake.

\section{Adherence is a dynamic behaviour}

- Adherence levels change over time.

- Adherence is determined by a matrix of inter-related factors that shift over time. No factor stands alone.

- Adherence requires an integrated, multidisciplinary approach: physicians, nurses, counselors and pharmacists.

- Adherence requires a combination of adherence promoting strategies. 
MODULE 2

Patient Preparation for Adherence 

MODULE 2

\section{Patient Preparation for Adherence}

\section{OBJECTIVES}

To provide trainees with an understanding of

- Initial assessment of the patient

- Barriers to adherence

- Patient preparation for starting antiretroviral therapy.

\section{ACTIVITIES}

1. Brainstorming: Discuss barriers to adherence.

$30 \mathrm{~min}$.

2. Presentation and discussion on patient assessment, barriers and patient preparation for antiretroviral therapy. $\quad 60 \mathrm{~min}$.

3. Review. $15 \mathrm{~min}$. Total $1 \mathrm{hr} 45 \mathrm{~min}$.

\section{HANDOUTS}

- Additional reading material on Module 2: Patient Preparation for Adherence

- Power Point presentation for Session 2

- Barriers and ways to address them 


\section{Activity 1: Brainstorming}

This activity is designed to improve trainees' knowledge about patient preparation prior to initiating antiretroviral therapy. The trainer will build on the information provided in Module 1 . The trainer will lead the participants through a brainstorming exercise to identify barriers to adherence and the role of the different health providers. The trainer will ask participants to list possible barriers for PLHA and ways to address them. The trainer will use lead questions that are based on the Additional Reading Material provided in this Module enabling trainees to recall the issues discussed when going

METHODOLOGY: Group discussion

MATERIALS:

- Flip charts

- Handout on Barriers

DURATION $30 \mathrm{~min}$. through the reading material.

In case the group is too large, this activity may be done in two groups. Each group will present their findings.

Handouts may be given out after the discussion.

\section{List of Barriers to Adherence and Ways to Address Them Handout for Group Discussion}

1. Communication difficulties (language, cultural differences, patient attitudes regarding treatment efficacy, lack of comprehension about treatment plan or regimen)

i. Discuss in an open and non-judgmental way

ii. Provide patients with scientific basis for treatment

iii. Repeat and paraphrase

iv. Use counselors who speak the same language and understand the cultural context of the patient

2. Literacy levels

i. Verbal repetition of adherence message, treatment plan and regimen

ii. Use patient literacy materials

iii. Use dummy pills for demonstration

iv. Review information with patient

3. Inadequate knowledge or awareness about HIV disease

i. Provide patients with scientific information about HIV disease

ii. Review information with patient

iii. Use examples 


\section{Inadequate understanding about effectiveness of medications}

Inform patient and bring change in attitudes and understanding of effectiveness of medications

5. Lack of social support

i. Establish contact with PLHA support groups

ii. Link with community health workers and home-based care services

iii. Link with charitable institutions, Faith Based Organisations

6. Discomfort with disclosure of HIV status

i. Counseling patient to support disclosure

ii. Identify other support persons like friends or peers if patient unable to disclose to the family

7. Difficult life conditions (lack of income, housing and food; lack of support for childcare)

i. Establish contact with PLHA support groups

ii. Link with community health workers and home-based care services

iii. Link with charitable institutions, church programs

8. Alcohol and drug use

i. Counseling_emphasize link between alcohol, ARV medications and liver damage

ii. Family support

iii. Peer group support programs, church programs

iv. Medical consultation-de-addiction programs

9. Depression and other psychiatric problems

Refer to physician for treatment

10. Negative or judgmental attitude of providers

Training of providers

11. System barriers (drug stock-out, shortage of staff, health facility closed) 


\section{Activity 2: Presentation and Discussion}

The presentation will focus on risk assessment and patient preparation to start treatment.

The presentation will cover issues presented in this module so that trainees recall the issues presented when reading the material.

Discussion can be interwoven with the presentation to form an interactive session. The discussion will focus on patient factors: knowledge of HIV disease, perceptions about disease severity, commitment to take treatment, self-efficacy, barriers etc. Some of these issues have been covered in Module 1; the trainer will build on earlier knowledge during this session. Participants will be encouraged to discuss the issue with relevance to local conditions that may pose barriers to adherence.

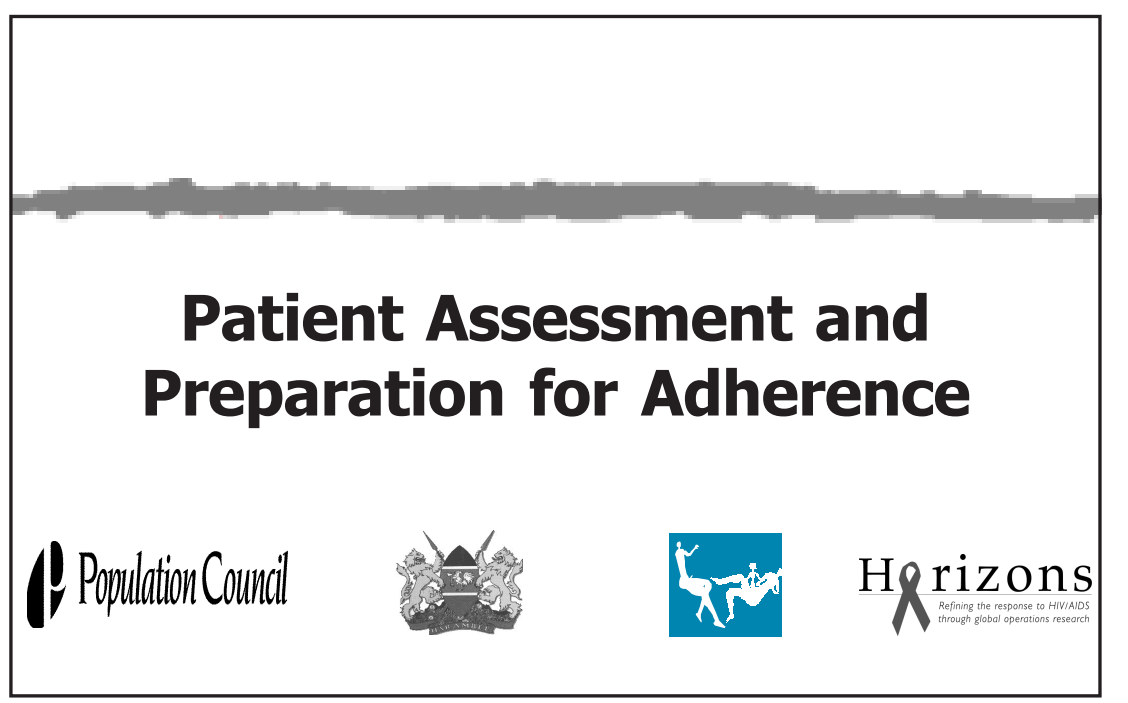




\section{Training Objectives}

\section{At the end of this session participants should have a basic understanding of}

$>$ Initial assessment of the patient

> Barriers to adherence

$>$ Preparation of the patient

\section{Why assess the patient?}

HAART is a complex treatment to be taken life-long We need to know:

$>$ Does the patient understand his disease?

$>$ Is the patient ready to make a commitment to a life-long treatment?

$>$ What are some of the problems the patient may have that will prevent him/her taking medications regularly?

\section{Initial assessment of a patient (1)}

- Learning about the patient's health status Detailed medical history includes:

$>$ General physical health

$>$ Past illnesses - OIs, hospitalizations

$>$ Mental health - depression, dementia

$>$ Substance abuse - alcohol, drugs

$>$ Other medications - prior use of ART, experience with adherence 


\section{Initial assessment of a patient (2)}

- Learning about the patient's beliefs and attitudes about HIV infection and treatment. What does the patient think about:

$>$ Effectiveness of HAART

$>$ Commitment to treatment

> Perceptions about seriousness of his/her illness

$>$ Continuing preventive and protective behaviour

\section{Initial assessment of a patient (3)}

- Learning about the sources of social support

$>$ Lives with family/lives alone

$>$ Support from family and friends

> Support from outside the family - NGOs, church, workplace etc.

$>$ Disclosure of his/her HIV status

\section{Initial assessment of a patient (4)}

- Learning about socio-economic status

Housing

$>$ Employment and income

$>$ Dependants

> Migrant status and home district 


\section{Barriers to adherence}

\section{Barriers to adherence (1)}

Communication difficulties

Literacy levels

Inadequate knowledge or awareness of HIV disease

Inadequate understanding of treatment regimen

\section{Barriers to adherence (2)}

Discomfort with disclosure of HIV status

> Patient attitudes and beliefs in treatment efficacy

Depression and other psychiatric problems

Alcohol and/or active drug use 


\section{Barriers to adherence (3)}

Difficult life conditions

Unstable living conditions

$>$ Negative or judgmental attitude of health providers

System barriers

\section{Patient preparation}

\section{Patient preparation (1)}

Requires 2-3 (even 4) sessions with the patient prior to starting HAART

$>$ Sets the ground for better adherence long-term

>ngoing process with a two-way exchange between patient and provider 


\section{Patient preparation (2)}

\section{Components}

Establishing trust between patient and provider

Introduction to the treatment and adherence program

\section{Patient preparation (3)}

Discussion about:

> Patient's present health status

> Past experience with ART and adherence

$>$ Expected changes in physical well being and biological markers with ART

$>$ Importance of adherence

\section{Patient preparation (4)}

Discussion about:

$>$ Patient's living conditions

$>$ Patient's daily routine

> Understanding of patient's beliefs and attitudes HIV disease, ART, preventive behaviour

> Identification of potential barriers \& ways to address them 


\section{Patient preparation (5)}

Making a treatment plan

$>$ Treatment regimen

$>$ Follow-up plan

$>$ Integrating treatment into patient's daily routine

Discussion about proposed adherence strategy

\section{Assessment of patient readiness}

\section{Before starting ART}

$>$ Patient should demonstrate an understanding of his/ her disease and health status

$>$ Patient should demonstrate an understanding of his/ her treatment regimen and follow-up plan

> Patient should appear to make a commitment toward adhering to treatment

$>$ Potential barriers should have been identified and addressed to the best possible extent

$>$ Patient should appear to be ready to start HAART

\section{Multidisciplinary Adherence Team}

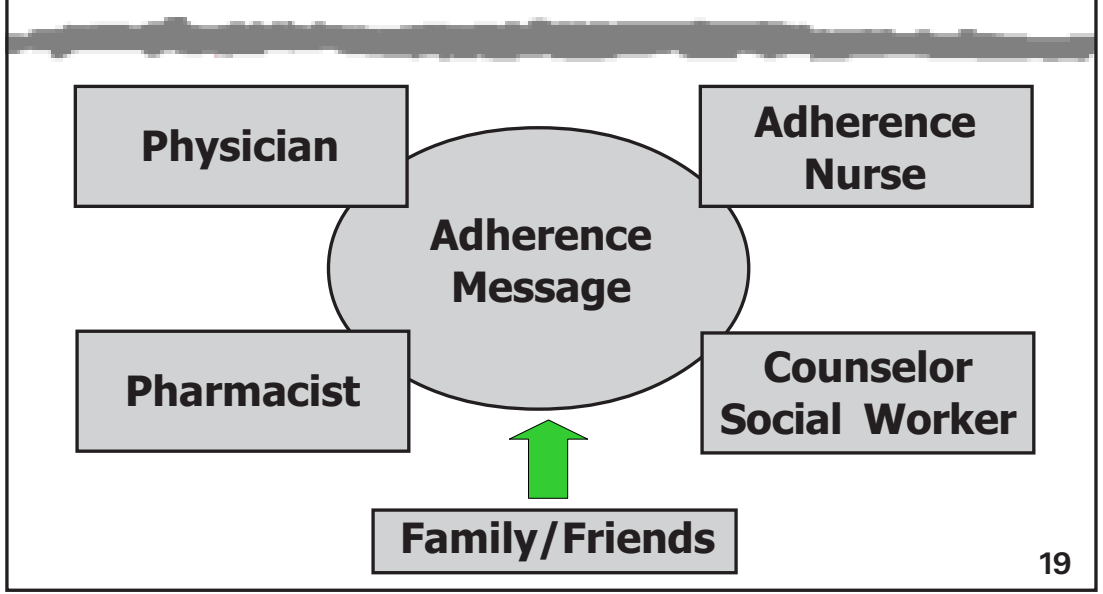


METHODOLOGY:

Volunteer Discussion

MATERIALS:

Flip Chart, Additional

Reading Material

DURATION $15 \mathrm{~min}$.

\section{Activity 3: Review: 0 \& A}

Review discussion of the day. Ask two volunteers to sum up the main points for the day. Allow trainees to ask questions, seek clarifications or additional information. Give out additional reading material. Encourage trainees to read material and discuss issues the following morning prior to the next training session. 


\section{ADDITIONAL READING MATERIAL}

\section{PATIENT ASSESSMENT}

HAART is a complex treatment with multiple medications that once started need to be taken long-term. It is extremely important to take time to assess and prepare the patient for this treatment. Setting the ground for adherence to treatment begins before antiretroviral therapy is started. Treatment programs need to have a consistent approach to patient readiness assessment.

The initial assessment of patients forms the basis for setting up a successful treatment adherence plan. During the assessment the counselor should aim to learn as much as possible about the patient's health and psychosocial background.

Initial assessment should include the following points:

- Learning about the patient's health through a detailed medical history.

- Learning about the prior use of antiretrovirals and other medications.

- Learning about the patient's beliefs and attitudes about HIV and treatment.

- Learning about the sources of social support.

- Learning about the socio-economic situation of the patient.

- Identifying barriers to adherence.

\section{PATIENT PREPARATION FOR TREATMENT}

Patient preparation is an important step that goes a long way in getting patients to take treatment correctly as prescribed over the long term. Preparation includes the initial assessment of the patient and can be done over three to four visits before initiating ARV therapy.

The preparation process is important for both patients starting treatment for the first time (treatment-naïve), as well as those who may have used antiretrovirals in the past (treatment-experienced). For treatment-naïve patients, the preparation process helps patients (i) understand the challenges of taking HAART, (ii) to think through the impact treatment will have on their lives, and (iii) to help patients make a commitment to long-term treatment. For treatment-experienced patients the preparation process helps (i) to re-evaluate their commitment to taking treatment, (ii) to identify potential and actual barriers, (iii) to address these barriers and adhere to treatment. 
The Health Belief Model of behaviour change is based on the theory that persons usually perceive a threat to their health (in terms of severity and susceptibility) and expect certain outcomes before they adopt new behaviours and develop the self-efficacy to make the change. Based on this theory, the process of behaviour change in a person is thought to have five stages:

- Pre-contemplation: when the person is unaware or not interested in changing behaviour,

- Contemplation: when the client thinks about behaviour change,

- Preparation: when a person actively decides to change,

- Action: the person works at changing behaviour,

- Maintenance: when a person is able to sustain behaviour change for more than 6 months.

The preparation process works on these principles. It gives patients time to understand their disease and its severity and to understand the need to take medications to achieve health benefits. It helps the patient to make a commitment to take treatment regularly and correctly to achieve desired health outcomes. The preparation process helps to empower patients prior to starting treatment.

Preparation of the patient includes the following.

\subsection{Establishing Trust Between Patient and Provider}

The first step in preparing the patient is to establish trust. This is an ongoing process that is strengthened over time. An assurance of confidentiality, a non-judgmental attitude, mutual respect and clear communication of information contributes greatly to developing a trusting relationship between provider and patient.

\subsection{Introduction to the Treatment and Adherence Program}

A discussion about the ARV program, health facility, medication availability, laboratory facilities and support services helps to familiarize the patient with the treatment program. An introduction to the staff providing services and familiarizing the patient with the clinic layout is an important step in putting the patient at ease.

It is important to emphasize that disease progress can be delayed with treatment if taken regularly. Patients should be given a positive message. 
Patients who have adhered well to their treatment are in good health more than decade after they started treatment.

\subsection{Assessing the patient's health status}

Learn about the patient's health through a detailed medical history. This includes an assessment of general health status, past illnesses and hospitalizations and mental health. Patients who have experienced serious infections or hospitalizations may perceive their illness as serious and adhere better to treatment. Patients with severe mental illness may need help with taking medications regularly.

\section{a. Overall health}

A discussion on the overall physical and mental health status, ability to be in control of his/her life, and ability to conduct routine daily activities sets the stage for the discussion on the importance of taking medications regularly. A detailed medical history forms the basis for understanding some of the barriers to adherence.

\section{b. Disease stage}

A discussion on past opportunistic infections the patients may have had and what it implies in terms of disease progression helps patients understand the severity of their illness and the need to take medications correctly. It is important to emphasize that progress of the disease can be delayed with treatment if taken regularly and correctly.

The modified WHO staging for HIV infection and disease uses clinical and laboratory staging to determine disease stage (Tables 1 and 2). The modified WHO staging has been used for predicting progress to stage IV disease. The predicted time for disease progression from stage III to IV is approximately 2 years and the estimated survival for patients in stage III and IV is 3.7 years and 1.7 years (Table 3). Even in cases of patients with advanced disease, care must be taken not to discourage them with predications of lifeexpectancy.

When started in time, HAART delays disease progress and prevents death.

Patients should be given a positive message.

Patients who have adhered well to their treatment are in good health more than decade after they started treatment. When started very late in the disease process, medications may not be able to control disease progression. 
Information on WHO disease stage and estimated survival is given in the following tables.

\section{Table 2.1: WHO Clinical Staging for Disease}

Stage 1 Asymptomatic, peripheral general lymphadenopathy, acute HIV

Stage 2 Loss of weight $<10 \%$, minor mucocutaneous lesions, zoster within last 5 years and recurrent upper respiratory illnesses

Stage 3 Loss of weight $>10 \%$, chronic diarrhea $>1$ month, thrush, oral hairy leukoplakia, TB within past 1 year, severe bacterial infections

Stage 4 Wasting syndrome, any ADI (AIDS Defining Illness)

WHO Wkly Epid Rec 1990 65:221

$\begin{aligned} & \text { Table 2. 2: Modified } \\
& \text { Disease }\end{aligned}$
\begin{tabular}{llccccc} 
CD 4 & Lymphocytes & WHO 1 & WHO 2 & WHO 3 & WHO 4 \\
\hline$>500$ & $>2000$ & I & I & II & IV \\
$200-500$ & $1000-2000$ & II & II & III & IV \\
$<200$ & $<1000$ & III & III & IV & IV \\
& & & Montaner J et al. AIDS 1992 & $6: 719$
\end{tabular}

\section{Table 2.3: Evaluation of Modified WHO Staging System for HIV Infection and Disease}

Estimated time for disease progression to stage IV

$\begin{array}{ll}\text { Stage I to IV } & 9.5 \text { years } \\ \text { Stage II to IV } & 6.5 \text { years } \\ \text { Stage III to IV } & 2.0 \text { years }\end{array}$

Estimated survival

Stage I

Stage II

Stage III

Stage IV
11.2 years

8.2 years

3.7 years

1.7 years

Schecter M T et al. JAIDS 1995 8:474 


\section{c. CD4 counts}

It is important to discuss the CD4 cell count with patients. The discussion should cover the following points:

- CD4 cells counts are a measure of the patient's immune status,

- HIV attacks CD4 lymphocytes,

- lower CD4 counts signify advanced HIV disease,

- CD4 cell counts increase with treatment.

The patient should be explained how lower CD4 counts are associated with an increase in the number of episodes of opportunistic infections (OIs) and continued disease progression; and how higher CD4 counts indicate a lower risk of OIs and improved health status. Patients should know their CD4 cell count and monitor how it changes with treatment. Patients who have knowledge about their disease tend to exhibit higher levels of adherence to treatment.

\section{$C D 4^{+} T$ Cell counts}

CD4 cells are lymphocytes with CD4 receptors that play a critical role in the function of the immune system to fight off infections. They are also called $\mathrm{T}$ cells.

$>$ The virus is particularly attracted to CD4 cells and destroys them, thus lowering the body's immunity against infections. Measuring the number of CD4 cells in the body is one method of determining how well the immune system is functioning. A person with a normally functioning immune system has between 600-1200 CD4 cells.

$>$ When CD4 counts fall to below 200, people who have HIV infection and are not on preventive medications may develop a host of opportunistic infections (PCP - AIDS related pneumonia, recurrent herpes zoster, fungal infections, cancerous skin lesions etc.).

$>$ Treatment with antiretroviral medications reduces the number of virus in the body and thereby decreases the destruction of CD4 cells. With successful treatment, CD4 cell counts increase, restoring immune function and patients experience fewer or no opportunistic infections. CD4 cell counts can rise anywhere from 50-150 cells or more with successful treatment. This rise may take several months as it depends on how severely the patient's immune system was affected at start of treatment.

Patients with CD 4 cell counts at or below 200 cells $/ \mathrm{cm}^{3}$ are eligible to receive antiretroviral medications in this program. 


\section{d. Viral load (VL)}

It is desirable to discuss the viral load with patients even when it may not yet be available for routine monitoring. The discussion should cover the following:

- viral load measures the amount of HIV in the blood,

- higher viral load levels signify increased risk of transmitting infection,

- treatment with ART results in viral load reduction,

- patients start to feel better when viral load decreases.

The patient should understand how viral load measurements change in response to effective treatment.

\section{Viral Load}

Viral load tests measure the amount of HIV virus in the bloodstream. If the viral count is high, it means that the virus is in a period of greater activity, replicating (producing copies of itself) and further infecting new cells.

Viral load tests when available (they are very expensive and require advanced laboratory facilities) are used to determine the need for therapy and assess prognosis.

$>$ Successful treatment with highly active antiretroviral therapy (3 drug cocktail) should result in a reduction in viral load. Viral load should / can go down ten-fold in the first 8 weeks and then further to undetectable levels in 16-20 weeks.

$>$ The rate of viral load decline is affected by the baseline CD4 cell count, initial viral load, potency of the regimen, adherence to treatment, prior antiretroviral medication use and the presence of OIs.

$>$ Viral loads tend to be the highest during initial acute HIV infection (acute HIV syndrome) and in advanced disease.

\subsection{What Patients Can Expect to See with Treatment}

A discussion on the changes in the CD4 counts and viral load measurements with successful treatment should be included. Emphasize the connection between regular and correct medication taking with improving immune function, improvements in general physical conditions, weight gain, fewer opportunistic infections and slowed progression to AIDS. 


\subsection{The Importance of Adherence}

Preparatory counseling should emphasize the importance of adherence to treatment in order to achieve viral load suppression and treatment success. Patients should understand the link between regular intake of medication or higher adherence with a decrease in viral load, increase in CD4 cell counts and treatment success. Consequences of non-adherence such as ongoing increase in viral load, decrease in CD4 cells and immune function and disease progress should be discussed. The counselor should emphasize the need for taking every dose every day and correctly with respect to time intervals and dietary instructions. A twice-daily dose is to be taken 12 hours apart, a thricedaily dose to be taken 8 hours apart etc.

\subsection{Prior Use of Antiretrovirals}

A discussion on prior use of antiretrovirals and experience with adherence to treatment is important. Patients with prior adherence problems or irregular use of antiretroviral medications would need added support and counseling.

Information on other medications that the patient may be taking is required to assess drug interactions and side effects.

\subsection{Patient's Beliefs and Attitudes}

Learn about the patient's beliefs and attitudes about HIV and treatment. Positive attitudes and beliefs support adherence. Patients who believe that treatment is beneficial, are able to make a commitment to long-term treatment and are confident that they will be able to take medications correctly and regularly, tend to adhere better to treatment.

\subsection{Social Support and Socio-Economic Situation}

The initial assessment and preparation should include a discussion on the sources of social support for the patient. Does the patient live alone or with his family? Has s/he disclosed her/his HIV status to the family? Does the patient have a friend or family member that s/he trusts and expects support from? The discussion should include sources of support from outside the family such as NGOs, PLHA support groups, religious or faith based organizations or workplace programs etc. 
Learn about the socio-economic situation of the patient: housing, employment and income, number of dependent family members, migrant status, living conditions - factors that may influence regular and correct intake of medications.

It is important to discuss the patient's daily routine (employment, work timing, eating and sleeping pattern), HIV confidentiality issues at place of work and at home, medication storage and travel plans so as to identify areas where patients may have problems and need support. An understanding of the patient's daily routine and lifestyle helps to better integrate medication intake into the daily routine. Treatment reminder cues can be identified based on the patient's daily routine. Treatment reminder cues include tying medication intake to mealtime or specific routine activity such as leaving for work, notes written to oneself and placed at strategic points in the house, medication kept at a strategic location in the house.

\subsection{Establishing a Treatment Plan}

i. A discussion about the treatment regimen should cover the following points: medication names, dosing instructions, food and fluid intake requirements, and storage of medications. It is extremely important for the patient to know and understand their treatment regimen to enable them to take an active role in managing their HIV disease.

ii. A discussion about potential side effects and ways to manage them; when to seek care and how to contact providers should be included. Preparing the patient in advance about the side effects, that they might expect to see, removes the surprise or fear and prevents patients from stopping medications on their own.

iii. A discussion on the plan for routine follow-up should be included. Counselors should establish a contact system so patients can contact the provider in the case of need: medication side effects, illness, psychosocial problems etc. Providers may also need to contact the patient in case of missed appointments. Telephone numbers and addresses should be exchanged. Patients should be encouraged to discuss travel plans in advance so that extra medications can be issued to cover periods away. 


\subsection{Discussing the Proposed Adherence Strategy}

A discussion, early in the preparation process, on the adherence promoting strategies to be used, helps to increase acceptability and commitment. A range of strategies have been discussed in Module 1.

Family support should be encouraged for all patients. Patient preparation should include the adherence promotion strategy to be used for the client (tools such as checklists, pill diaries, pill boxes; modified DOT, buddy system etc.).

\section{IDENTIFYING BARRIERS TO ADHERENCE}

Identifying barriers to adherence forms an essential component of patient assessment and patient preparation. Barriers vary from person to person and within the same person from time to time. The treatment preparation process should ensure that potential or actual barriers are identified. The patient and provider can work together to address these barriers at the patient level, while the health system can address the barriers at the service delivery level.

Barriers to adherence could include:

\section{a. Communication problems}

Communication difficulties may arise from language and cultural differences. Communication difficulties could also arise when the patient's attitudes and expectations regarding HIV and treatment are different from those of the providers. Some patients may be defensive about their lifestyle and exhibit negative attitudes. This may be seen among marginalized or stigmatized groups.

How to address the barrier: Discussion in an open and non-judgmental way, paraphrasing and repeating information, providing patients with a scientific basis for HIV treatment and related issues helps patients develop selfconfidence and positive attitudes. Understanding cultural differences and

Barriers vary
from person to
person and
within the
same person
from time to
time.
providing counseling in the patient's dialect and language help to solve communication problems. 


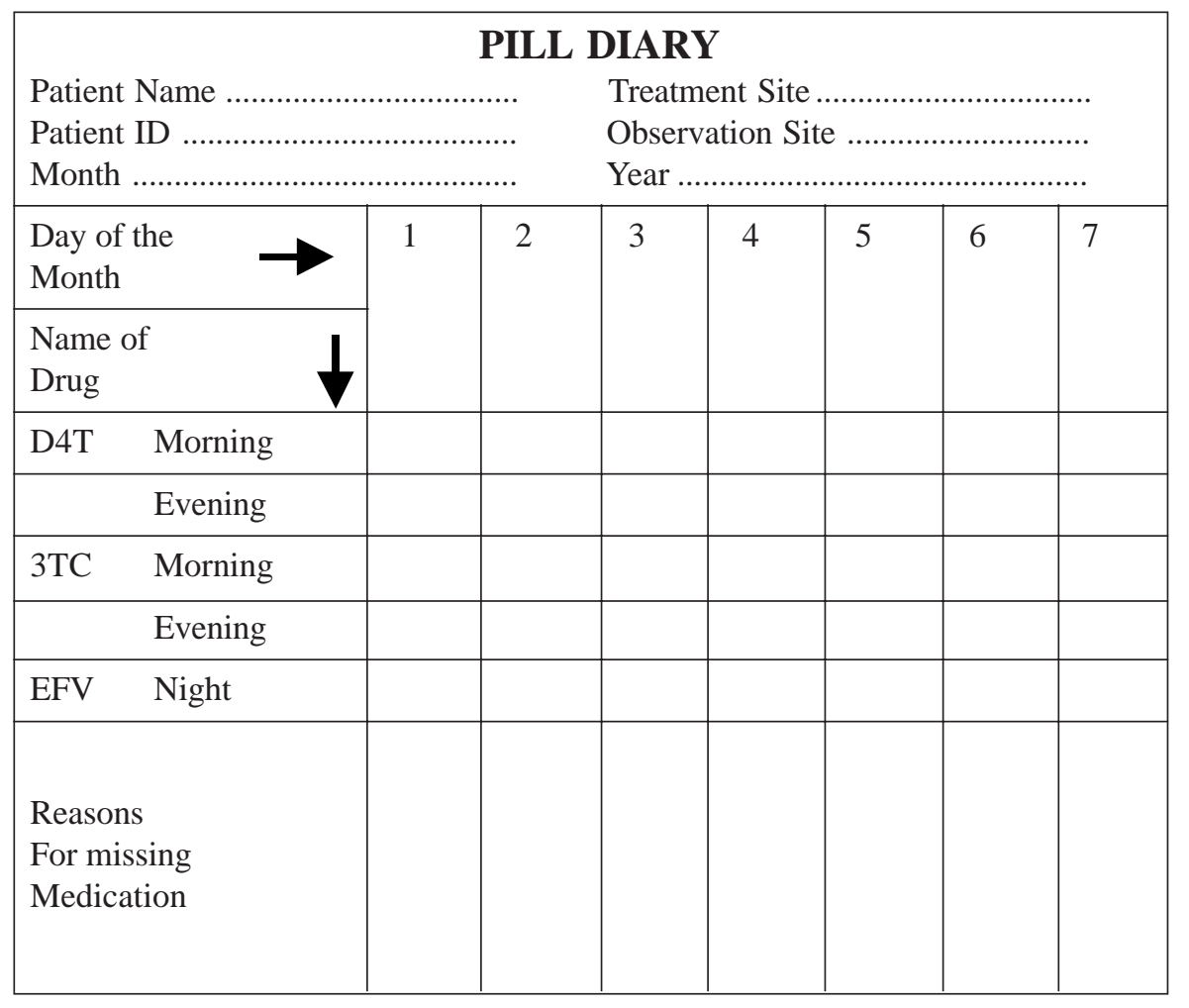

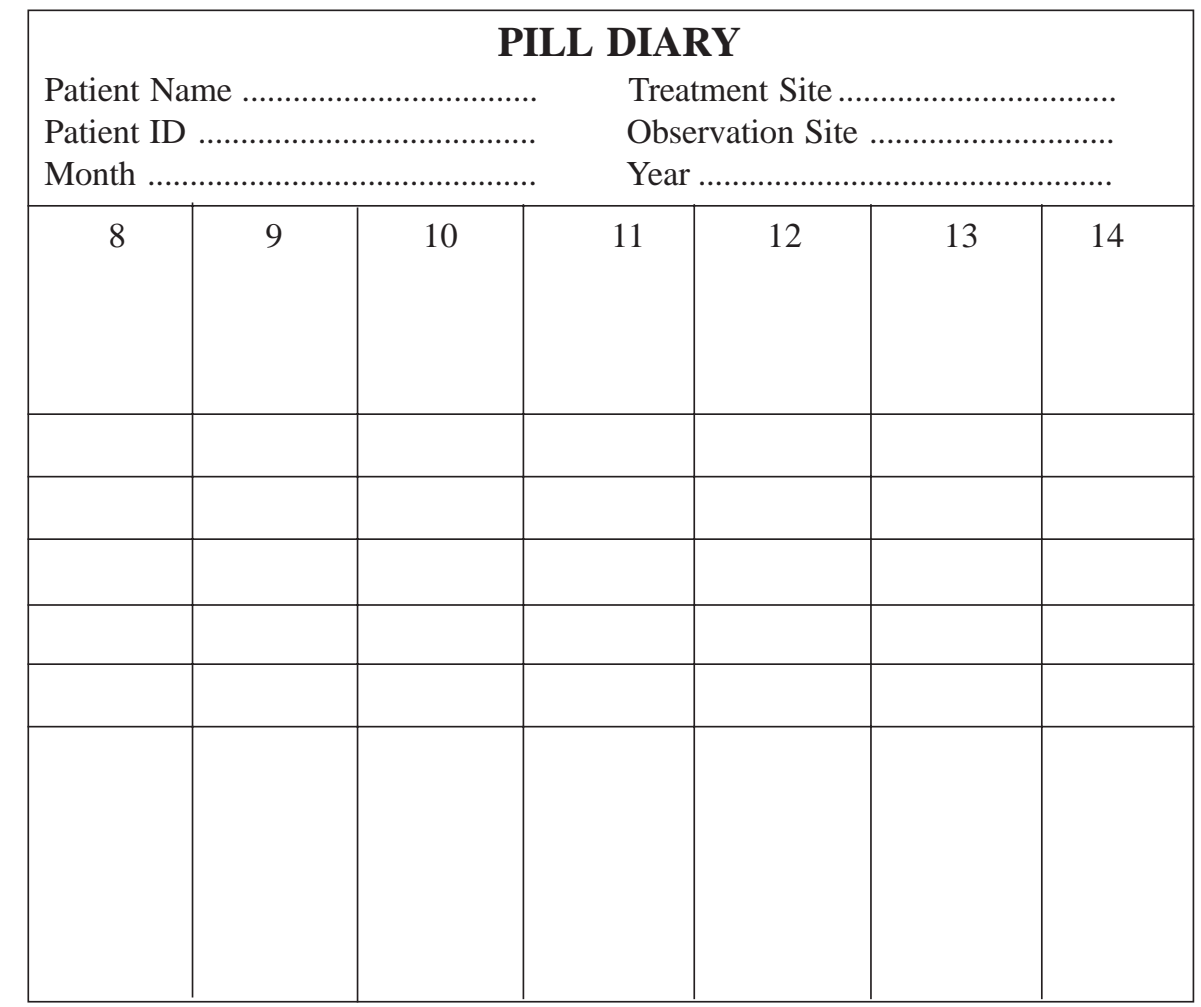

Fig. 2.1: Pill Diary 


\section{b. Literacy levels}

Patients with low literacy levels may not completely understand their disease, its challenges and complications. Patients may not comprehend instructions provided.

How to address the barrier: Use verbal repetition of the adherence message, treatment plan and regimen. A practice session with dummy pills may help patients. Using pictorial representation of the message may be helpful. Reviewing written information with each patient, describing technical terms in simple language and asking patients to repeat instructions may be helpful. Efforts should be made to avoid uncomfortable situations where the patient's lack of or lower levels of literacy are revealed. This encourages a sense of trust in the provider and self-efficacy in the patient.

\section{c. Inadequate knowledge or awareness about the disease and effectiveness of medications}

Patients who understand their HIV disease and the relationship between treatment, adherence and successful outcomes do better than patients who do not have such an understanding. Patients who believe in the effectiveness of medications also do better with treatment.

How to address the barrier: Discussion in an open and non-judgmental way, paraphrasing and repeating information, providing patients with a scientific basis for HIV treatment and related issues will help patients develop selfconfidence. Presenting a case study or experience from other patients may also help patients develop positive attitudes and confidence in the effectiveness of treatment.

\section{d. Unstable living conditions and lack of social support}

Patients may be living alone, living in shared accommodation or living on the street. Unstable living conditions pose a major barrier to proper medication intake and storage. These patients also tend not to have family or outside support thereby missing out on a caring atmosphere, proper nutrition and stability in their personal lives.

How to address the barrier: Establishing contact with PLHA support groups, if the patient is willing, may be helpful in getting some support. Linking the patient with a home-based care program and CHWs (Community Health Workers) may provide some psychosocial support and nursing care. Support programs run by faith based organizations, such as food donation programs, may provide an additional source of support. 


\section{e. Discomfort with disclosure of HIV status}

Disclosure of HIV status is an important factor influencing adherence. Fear of rejection or discrimination may prevent PLHA from disclosing their status to family members and friends thereby losing out on social support. Patients may not want to take their medications in the presence of colleagues at work or family members at home and so choose to skip that particular dose of medication.

How to address the barrier: Counseling can help the patient to overcome some of these fears and help with disclosure to the family or friends. Once the patient is ready to do so, counseling for family members to facilitate disclosure may be required. It is important that these family members are identified by the patient. In cases where patients are not ready to disclose their status, counselors can help patients identify a person or two outside the family who could provide psychosocial support, for example peers, friends, PLHA support groups.

\section{f. Difficult life conditions}

Patients who do not have housing, are unemployed, have very modest or no financial means, may perceive the lack of income, housing and food, support for childcare as more urgent needs than taking medications properly.

How to address the barrier: While it may not be possible for the health worker to directly address these problems, linking patients with church programs, PLHA support groups and the home-based care program may offer some help. Some church programs provide food donation and PLHA groups have income generation activities.

\section{g. Alcohol and drug use}

Patients with heavy alcohol intake or active drug use have problems in adhering to treatment - forgetting to take medications on time or correctly.

How to address the barrier: Counseling is an important tool. Patients should be provided scientific information on the link between alcohol, ARV drug metabolism in the liver and resulting exacerbation of liver damage. It may become necessary to stop or change ARV medications if liver damage occurs. Discussion in an open and non-judgmental way is essential. Linking patients with PLHA support groups and peer group interventions may be helpful. Counselors would need to ask a family member to remind the patient about 
medication intake (only when the patient has disclosed his/her HIV status). Referring patients to active de-addiction programs, where available, is useful.

\section{h. Depression and other psychiatric problems}

Patients with depression and other psychiatric illness may have difficulties in adhering to treatment. Patients with advanced HIV disease may have HIV disease-related conditions such as AIDS dementia, which may prevent patients from caring for themselves and taking medications regularly and correctly. Patients may suffer from residual confusion after an episode of meningitis or encephalitis.

How to address the barrier: Active depression can be treated with antidepressants. Physicians can assess the patient and provide relevant medical care. Treatment with ARV in itself helps to resolve some conditions. AIDS dementia may not improve despite ART and these patients require additional support. Enlisting support, to help patients take their medications on time, from the family, community health workers, and PLHA support groups would be required.

\section{i. Negative or judgmental attitudes of providers}

Patients who perceive their providers as having antipathy towards them or a negative and discriminating attitude are understandably reluctant to adhere to treatment and maintain a regular schedule of follow-up care.

How to address the barrier: Training of providers will help to overcome this barrier. Regular staff meetings to discuss the follow-up of patients may help providers to understand the issues better.

\section{j. System barriers}

Patient adherence may be influenced by health system barriers, such as: health facility being closed, no drugs in stock, patients being turned away due to staff being too busy etc.

These barriers need to be addressed by the management. Counselors may help by bringing these issues to the administration's notice. 


\section{NUMBER OF PREPARATORY VISITS}

For adequate patient preparation, two to three or even four preparatory visits may be required where patients receive adherence counseling and practice with medications. Following the final preparatory visit, the treating physician and nurse counselor can assess patient readiness to initiate treatment. It may be best to initiate treatment when:

- The patient demonstrates an understanding of his/her disease

- The patient demonstrates an understanding of the treatment regimen

- The patient demonstrates an understanding of the link between adherence to treatment and successful treatment outcomes (such as improved immune status, increasing CD4 counts, decreasing viral load etc.)

- The patient is able to make a strong commitment towards adhering to treatment.

Although, some patients may require more than three sessions to be adequately prepared, it may not be possible to delay initiation of therapy any longer due to the disease already being at an advanced stage. Patients may also not be willing to delay initiation of therapy. In such situations, additional counseling sessions can be administered alongside initiation of therapy.

\section{THE MULTIDISCIPLINARY ADHERENCE TEAM}

HIV is a complex illness that has an impact on many aspects of an individual's health and life. Several factors influence adherence to treatment, necessitating a multidisciplinary approach involving physicians, nurses, counselors and pharmacists.

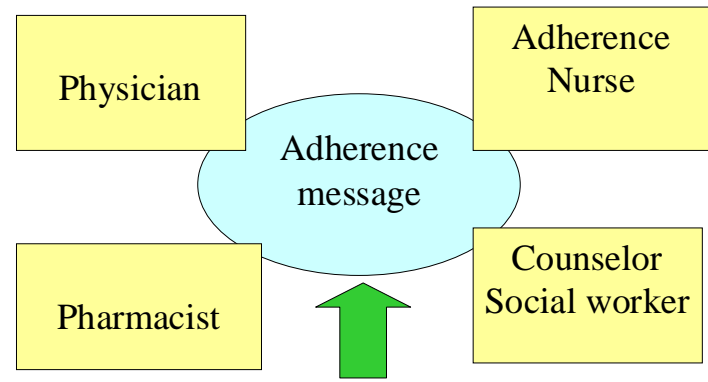

Family / Friends

Fig. 2.2: Multidisciplinary Adherence Team 
It is useful to have the message on adherence repeated at multiple points by the various providers involved in providing care. Enlisting support from family members and friends, where possible, is encouraged. A participatory approach where patients take part in making decisions regarding medications and adherence strategy has been seen to contribute to improving adherence.

\subsection{Role of the Physician}

- Leader of the case management team

- Main person to take decisions regarding

- Initiation of ART

- Continuation of therapy

- Treatment failure or non-response

- Side effects/adverse events and appropriate response

- Change of treatment regimen

- Adherence to treatment

- Prophylaxis therapy

- Responsible for overall health status of patient

- Provides information on adherence.

\subsection{Role of the Nurse Counselor/Nurse Case Manager}

- Adherence Counselor for individual patients working in close collaboration with the physician.

- Responsible for

- Adherence counseling for patients

- Adherence-related follow-up and data collection

- Adherence strategy to be used

- Liaising with different specialties involved in case management (e.g. TB services, dermatology, home based care).

- Informing physician of problem areas: side effects, adverse events and psychosocial problems.

\subsection{Role of the Pharmacist}

- Member of the treatment and adherence team

- Responsible for

- Dispensing of medications

- Treatment-related counseling

- Adherence counseling at time of dispensing treatment

- Checking out for side effects and adverse events

- Pill counts at time of medication refill. 
MODULE 3

Preparatory Adherence Counseling 

MODULE 3

\section{Preparatory Adherence Counseling}

\section{OBJECTIVES}

- To provide trainees with skills in the initial assessment of a patient

- To provide trainees with skills in preparatory counseling for patients prior to initiating HAART

\section{ACTIVITIES}

1. Brainstorming on adherence counseling-its nature and purpose and on attributes of an effective counselor

$30 \mathrm{~min}$.

2. Presentation on the content of counseling during first three sessions

3. Case studies through group discussions

$40 \mathrm{~min}$.

4. Review or summary $45 / 60 \mathrm{~min}$.

$15 \mathrm{~min}$.

Total Time: $130-145$ min.

\section{HANDOUTS}

- Additional reading material on Module 3: Preparatory Adherence Counseling

- Checklists for the three preparatory counseling sessions

- Effective counseling techniques handout

- Patient literacy materials

- Demonstration pill chart 


\section{Activity 1: Brainstorming}

This activity is designed to provide trainees with adherence counseling skills and to make them aware of the nature of the long-term relationship with the patient.

The trainer will build on the information provided in Module 2. Participants will break up into 2-3 groups and come back for a plenary. The trainer will lead the participants through a brainstorming exercise to understand the nature and purpose of adherence counseling, the attributes of an effective counselor and effective counseling techniques. The trainers will use lead questions that are based on the reading material provided in this module enabling trainees to recall the issues discussed when going through the reading material.

METHODOLOGY:

Small group discussion

MATERIALS:

Flip charts, handout on effective counseling techniques DURATION $30 \mathrm{~min}$.

\section{Handout for Effective Counseling Techniques}

Discuss the following techniques to make counseling more effective.

- Active attending or listening

- Reflection of feeling

- Questioning

- Paraphrasing

- Interpretation

- Repeating

- Summarizing

- Respecting

- Structuring or prioritizing

- Fixing goals 
METHODOLOGY: Presentation with interactive session

MATERIALS:

Power Point

DURATION $40 \mathrm{~min}$

\section{Activity 2: Presentation}

The presentation will focus on the topics that need to be covered in the first three adherence counseling sessions prior to initiating HAART and will cover topics presented in Module 3. The session should allow for an interactive discussion with trainees during the presentation with a special focus on the steps required to prepare the patient for starting HAART.

\section{Preparatory Adherence Counseling}
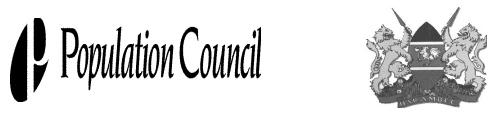

Horizons

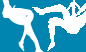

At the end of this session participants should have a detailed understanding of

Content of the three preparatory counseling sessions

Assessment of patient readiness to start treatment 

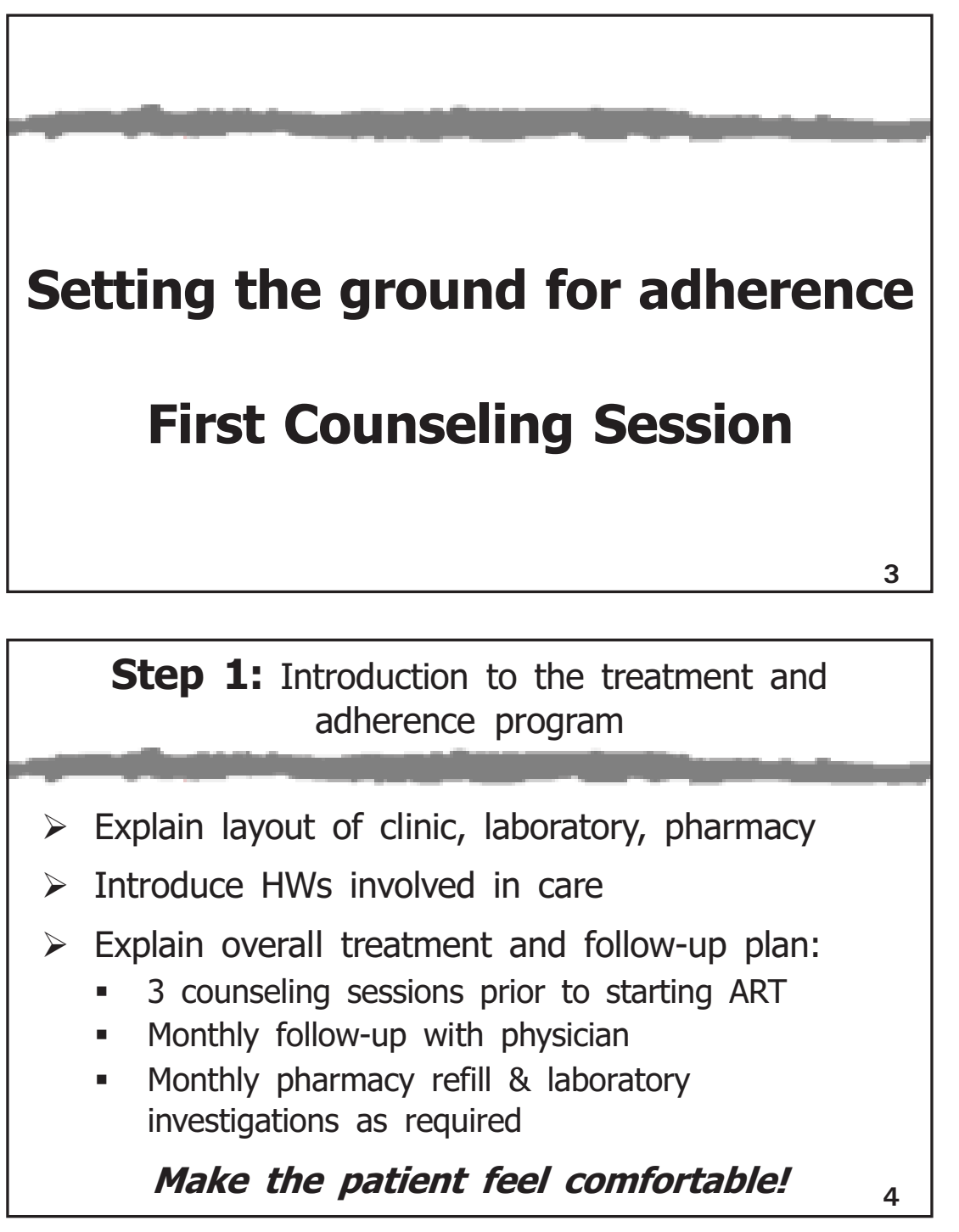

Step 2: Discuss patient's health status

\begin{tabular}{|l|}
\hline Step 2: Discuss patient's health status \\
$>$ Overall health and physical condition \\
$>$ Disease stage and past OIs \\
$>$ CD4 counts and viral load \\
$>$ Expected changes in health and CD4 counts \\
$>$ with regular ART \\
$>$ Importance of $>$ 95\% adherence
\end{tabular}




\section{Patient's health status (contd)}

> Past use of ARVs/Other medications

$>$ Alcohol/drug use

$>$ Pregnancy and family planning

$>$ Protective and preventive behaviour

During the session assess:

> Patient's beliefs and attitudes about HIV infection and treatment

$>$ Patient's mental health

Step 3: Discuss Patient's Living Conditions and Social Support

Employment and income

> Living condition - housing,

$>$ Disclosure of HIV status

$>$ Social support

> Dependants - other HIV infected persons

$>$ Migrant status and travel

Daily routine

Step 4: Discuss treatment plan

$>$ Treatment regimen

- Names and doses

- Instructions on food and fluid intake/restrictions

- Storage of medications

- Take all doses of all medications and do not share!

Side effects - discuss briefly, do not overwhelm the patient

$>$ Follow-up plan

- Next two counseling sessions

- Physician check up and investigations

- Contact information - HW and patient 
Step 5: Discuss the proposed adherence strategy

DAART (Modified DOT)

$>$ Treatment Buddy

Family involvement

Tools: Pill diary, treatment reminder cues etc.

Step 6: Identify barriers to adherence

Identify potential barriers from earlier discussion

Discuss ways to address barriers

Step 7: Fix a date for the next appointment

Continued Adherence Counseling: Second Counseling Session 


\section{Counseling Session 2}

Use an approach of continuing discussion and not an evaluation

Repeat information where necessary

Re-emphasize important issues

Use dummy pills to repeat instructions

\section{Counseling Session 2 (contd)}

\section{Step 1:}

Review and assess patient's understanding of his/her HIV disease and health status

\section{Step 2:}

Review and assess patient's understanding and recall of treatment and follow-up plan

\section{Counseling Session 2 (contd)}

\section{Step 3:}

Provide information on side effects

$>$ Expected side effects

$>$ How to manage them

$>$ When to seek care

$>$ How to contact health worker 


\section{Counseling Session 2 (contd)}

\section{Step 4:}

Review proposed adherence strategy

\section{Step 5:}

Review barriers and how to address them

\section{Step 6:}

Fix a date for the next appointment

\section{Assessment of patient readiness:}

\section{Third Counseling Session}

\section{Counseling Session 3}

\section{Step 1:}

Review treatment regimen and follow plan in detail:

$>$ Treatment regimen

$>$ Side effects and how to manage them

$>$ Follow-up plan

$>$ Adherence strategy

$>$ Contact system

$>$ Patient goals for adherence 


\section{Counseling Session 3 (contd)}

Step 2: Assess patient treatment readiness

$>$ Does the patient demonstrate an understanding of his HIV disease and health status?

$>$ Does the patient demonstrate an understanding of his treatment regimen and follow-up?

$>$ Does the patient appear to make a commitment to take treatment long term?

$>$ Does the patient have a major barrier to adherence? Has that been addressed?

Is he ready to start HAART?

\section{Counseling Session 3 (contd)}

\section{Step 3:}

Discuss patient readiness with physician

Refer patient to the pharmacy to receive ARVs

\section{Step 4:}

Set appointment for next visit

METHODOLOGY:

Small group discussion

MATERIALS:

Flip chart, checklists, patient literacy material, demonstration pill chart

DURATION $40 \mathrm{~min}$. (small group discussion-case studies) 60 min. (with role play)

\section{Activity 3: Group Activity: Case Studies}

Participants will be asked to break up into groups. Participants will be asked to discuss three case studies exploring adherence in preparatory counseling. Group leaders will present key points of their discussion. Where additional time is available, role-play can be done to enhance counseling skills. Participants will be asked to use the checklists, patient literacy material and pill demonstration chart. This session should take 60 minutes if role-play is included. 


\section{Group Activity Adherence Training Case Studies/Role Play}

Case Study 1: A 45-year-old man has been sent to you for counseling before starting HAART. This is his first preparatory session. He has some information on ARVs received from a radio program. He has done primary school, lives alone and still works full-time at a car repair workshop. He has not disclosed his status to his family; his wife left him 5 years ago. He drinks alcohol most evenings. He has a CD4 count of 160 cells and has had oral thrush, herpes zoster and TB. Please conduct the first preparatory counseling session.

Case Study 2: A 35-year-old woman has come for the third preparatory counseling visit. She is eager to start her ARVs. She has studied up to primary school and lives with her husband who is also infected but not on treatment. She works part-time as a maid. She has a CD4 cell count of 96 cells but does not understand what it means. She has had meningitis last month and was hospitalized for 10 days. Discuss the counseling needs for this patient. Discuss the use of dummy pills, a pill diary, reminder 'cues' and literacy material. Assess her treatment readiness.

Case Study 3: A 28-year old woman has come for her second preparatory counseling session. She works as a sex worker on the beachfront. She has a CD4 count of 35 cells and has had PCP, herpes zoster and meningitis in the last year. She is a widow, living in Bangladesh slum with two friends who also work as sex workers. She has completed high school. She has been losing weight steadily, feels weak and finds it difficult to concentrate. She has not been able to go to work for the last few weeks, as she has been feeling unwell. Her friends have been supporting her. She is keen on starting ART. She is planning to visit her family in upcountry next month.

If there is enough time, each group could conduct counseling for three cases.

Discuss:

- Disease knowledge and status

- Barriers

- Factors that might influence adherence

- Use of adherence enhancement tools-dummy pills, a pill diary, reminder 'cues' and literacy material. 


\section{Adherence Counselor Checklists for Preparatory Sessions}

\section{ADHERENCE COUNSELING CHECKLIST COUNSELING SESSION 1}

Client's name

Date of counseling session.

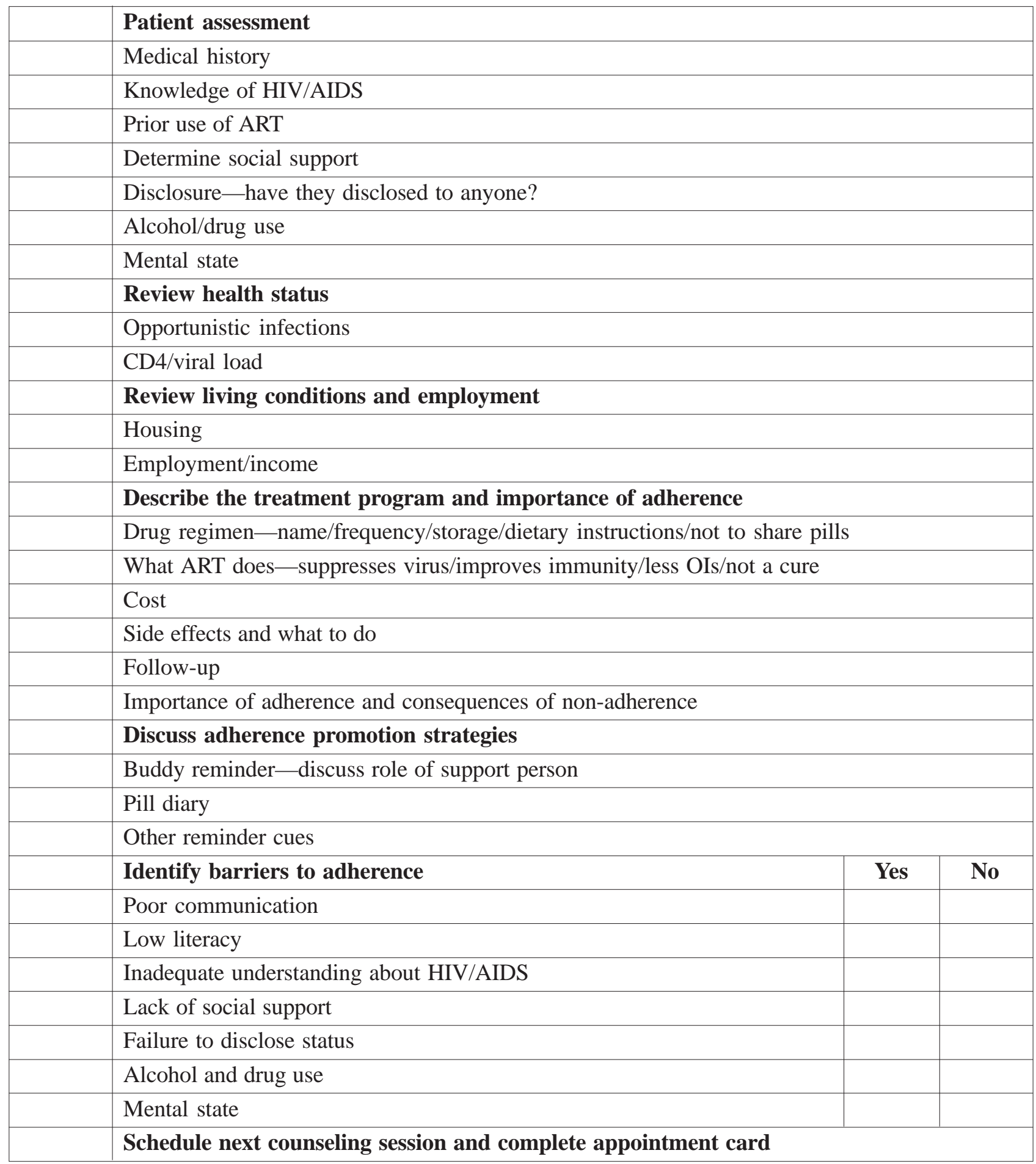




\section{ADHERENCE COUNSELING CHECKLIST COUNSELING SESSION 2}

Client's name

Date of counseling session.

\begin{tabular}{|c|}
\hline Review client's understanding of HIV/AIDS \\
\hline What is HIV and AIDS? \\
\hline Opportunistic infections \\
\hline CD4/viral load \\
\hline Effect of treatment \\
\hline Review the treatment program and importance of adherence \\
\hline Drug regimen \\
\hline Dummy pill demonstration \\
\hline What ART does-improves immunity/less OIs/ART not a cure \\
\hline Need for continued prevention \\
\hline Side effects and what to do \\
\hline Follow-up \\
\hline Importance of adherence and consequences of non-adherence \\
\hline Review proposed adherence promotion strategies \\
\hline Buddy reminder-discuss role of support person \\
\hline Pill diary \\
\hline Other reminder cues-discuss DAART \\
\hline Review barriers to adherence and progress made \\
\hline Poor communication \\
\hline Low literacy \\
\hline Inadequate understanding about HIV/AIDS \\
\hline Lack of social support \\
\hline Failure to disclose status \\
\hline Alcohol and drug use \\
\hline Mental state \\
\hline Take client's address and establish contact system with treatment centre \\
\hline Schedule next counseling session and complete appointment card \\
\hline
\end{tabular}




\section{ADHERENCE COUNSELING CHECKLIST COUNSELING SESSION 3}

Client's name

Date of counseling session.

\begin{tabular}{|l|l|}
\hline & Assess client's understanding of disease and readiness to start \\
\hline & HIV disease \\
\hline Opportunistic infections \\
\hline CD4/viral load \\
\hline Effect of treatment \\
\hline Commitment to adherence \\
\hline Review the treatment program and importance of adherence \\
\hline Drug regimen \\
\hline Dummy pill demonstration \\
\hline What ART does-improves immunity/less OIs/ART not a cure \\
\hline Need for continued prevention-condom use \\
\hline Side effects and what to do \\
\hline Follow-up \\
\hline Link between adherence and successful outcome \\
\hline Review proposed adherence promotion strategies \\
\hline Buddy reminder-discuss role of support person \\
\hline Pill diary \\
\hline Other reminder cues—discuss DAART \\
\hline Fill ART register, schedule next appointment and complete appointment card \\
\hline Refer to Pharmacy \\
\hline
\end{tabular}




\section{Prescriber/Physician Checklist after initiation of therapy}

1. Have I determined, in collaboration with the patient, that $\mathrm{s} / \mathrm{he}$ is ready to start treatment?

2. Have I prescribed the simplest regimen?

3. Have I explained to the patient details about dosing of medications? Have I reviewed with the patient any special instructions for taking and storing the medications?

4. Is the dosing schedule compatible with the patient's lifestyle?

5. Have I reviewed potential or common side-effects and considered preemptive treatment of predictable adverse events?

6. Did I ask the patient to repeat the medication names, dosing times and instructions?

7. Does the patient know how to contact the health-care team in case of problems or questions?

8. Does the patient know where and when to collect his medications?

9. Have I fixed the next appointment?

(Promoting Adherence to HIV ART. AIDS Institute, New York State Department of Health)

\section{Activity 4: Review}

Review the day's discussion. Ask two volunteers to come up and present main points for the day. Allow trainees to ask questions, seek clarifications or additional information. Give out the additional reading material. Encourage trainees to read material and discuss issues the next morning prior to next training session.

METHODOLOGY: Volunteer Discussion

MATERIALS:

Flip Chart, Additional Reading Material

DURATION $15 \mathrm{~min}$. 


\section{ADDITIONAL READING MATERIAL}

\section{Module 3: Preparatory Adherence Counseling}

\section{ADHERENCE COUNSELING: ITS NATURE AND PURPOSE}

In HIV/AIDS-related counseling, two people who are in no way related to each other meet to resolve a crisis, solve a problem or make decisions involving highly personal and intimate matters and behaviour. A counselor's emotional detachment is the key in assessing a client's case and providing unbiased information on HIV/AIDS to the client. Additionally, counseling is done during the pre- and post-test periods, after which patients may seek care elsewhere and the counselor withdraws.

Adherence counseling on the other hand is a long-term requirement of patients on ART. At this time, as scientific research stands, the virus cannot be eradicated from the body; therefore, the disease cannot be cured. It has become a chronic illness requiring management with medications. Anti-retroviral therapy has to be taken long-term. As is with other chronic illnesses, adherence to treatment changes over time and patients need support at different periods during their treatment. Adherence counseling forms a relationship between a counselor and client that is based on an understanding of the client's life situation and needs. This relationship is strengthened over time.

The objectives of adherence counseling are the following:

- Help patients develop an understanding of their treatment and its challenges.

- Prepare the patient to initiate treatment.

- Provide ongoing support for clients to adhere to treatment over the long term.

- Help clients develop good treatment taking behaviour.

- Help patients in setting goals for their treatment. 


\subsection{Attributes of a Good Adherence Counselor}

Adherence counseling as mentioned above is a long-term requirement of patients on ART. Adherence counselors need to have:

- Ability to listen

- Non-judgmental attitude

- Ability to provide scientific, accurate and complete information on HIV disease and antiretroviral treatment in an objective manner

- Ability to encourage patients to take decisions, make commitments to treatment

- Ability to develop a long-term trusting relationship with patients

- Problem solving ability

- Ability to link patients with other support services.

\subsection{Effective Counseling Techniques}

Adherence counseling is a challenge. It hinges upon the ability of the counselor to form a trusting and helping relationship with the patient. Counselors also need to have an in-depth understanding of ART (medications used, side effects, viral resistance, adverse events etc.). Effective communication is the counselor's principal tool. An ability to understand the client's life situation (psychosocial, socio-economic, support systems, treatment seeking behaviour, treatment readiness) and barriers to adherence is also essential.

Counseling should be done in a confidential setting where patients feel free to discuss their problems, behaviours and barriers. Including a family member in Sessions 2 and 3 may be useful to enlist social support only if the patient is willing and has disclosed his/her status to the family.

Some effective counseling techniques are described below.

\section{a. Active attending or listening}

Paying attention to the client's narrative helps in enhancing the client's selfrespect, establishing a trusting relationship, in assessing the patient for treatment readiness and in identifying some of the barriers to adherence that the client may have.

\section{b. Reflection of feeling}

The counselor must recognize feelings such as anger, frustration, and sadness or fear that are often associated with the illness (patients eligible for treatment 
are in an advanced stage of the disease with CD4 cell counts less than 200). Some of these patients may have recently been tested and diagnosed with HIV infection. These feelings further influence the patient's ability to make a commitment to take such treatment. The hope of treatment may push these patients to make commitments quickly without understanding the challenges of ART.

\section{c. Questioning}

Using questions to make communications clear so that both the problem and the solutions are clear can be a useful tactic. For example: "Do you mean ..."

\section{d. Paraphrasing}

Many people can tell they are being understood accurately if the counselor repeats what they have said in different words; for example, "You seem to be saying that you are afraid your family is not going to take care of you." The client might then agree with the interpretation. If not, the counselor can clarify the matter.

\section{e. Interpretation}

Often people avoid focusing on the real problem and talk around the issue. Interpretation can be used to redefine the issue from a different point of view or bring it out more clearly. The counselor can emphasize the important points. For example, "Of all the things you talked about today, it seems to me that you are most concerned about ..."

\section{f. Repeating}

At times of stress, people do not always understand everything they are told. ART is a complicated treatment. Preparation of patients prior to initiating treatment includes educating patients about the treatment regimen (names, doses, dosing instructions), side effects to watch out for and the challenges of treatment (such as the risk of treatment failure and viral resistance if taken irregularly, monitoring of treatment and other drugs used for prophylaxis and treatment of opportunistic infections). Repeating instructions may help the patients to understand better as well as give the patient a chance to ask questions or clarify doubts. Patients could also be asked to repeat instructions.

\section{g. Summarizing}

Summarizing the information given to the patient at the end of the meeting is a form of repeating and paraphrasing the information once again. This 
provides the patient with the important points in a concise form that helps the patient to organize the information and internalize it.

\section{h. Respecting}

It is important for the counselor to recognize that people see and cope with their predicaments in uniquely personal ways. Counselors should respect the patient's views, beliefs, cultural context, and build on them.

\section{i. Structuring or prioritizing and fixing goals}

Antiretroviral therapy is a complicated treatment regimen that has to be taken long-term. Medications have to be taken regularly, at fixed intervals with dietary restrictions. This requires a disciplined and committed approach on the part of the patients. Structuring means helping the patient to see how actions and outcomes are related. Prioritizing helps patients determine what needs to be done in which order so as to achieve the best outcomes. Counselors can help patients to set goals (short- and long-term) and plan treatment strategies for best outcomes.

\section{PRE-TREATMENT ADHERENCE COUNSELING}

Adherence counseling is challenging. It involves: (i) educating the patient about ART, (ii) preparing the patient to start treatment, (iii) initiating treatment, (iv) providing ongoing support counselling to help patients adhere to treatment in the long term.

The preparatory phase prior to initiating ART requires at least two to three clinic visits at an interval of 4-7 days. Some patients may require more than 3 preparatory counseling sessions. Baseline laboratory tests for initiating and monitoring ART can be done during these preparatory visits.

The counseling sessions will be as follows:

Preparatory Counseling Session 1: Setting the groundwork for adherence

Preparatory Counseling Session 2: Continued treatment and adherence counseling

Preparatory Counseling Session 3: Assessment of patient readiness and initiation of ART 


\subsection{Preparatory Counseling Session 1: Preparing the ground for adherence}

The first preparatory adherence counseling session is used to assess the patient as well as prepare the patient for initiating treatment. Adherence counseling should be done in consultation with the treating physician who plans the treatment. Establishing trust is the first step in preparing the ground for adherence, to be built upon and strengthened at subsequent meetings. An assurance of confidentiality, a non-judgmental attitude, mutual respect and clear communication of information contribute greatly to developing a trusting relationship.

The first session includes the following.

\section{a. Patient assessment}

The initial assessment of patients should include the following:

- Learning about the patient's health through a detailed medical history.

- Learning about the prior use of antiretrovirals and other medications.

- Learning about the patient's beliefs and attitudes about HIV and treatment.

- Learning about the sources of social support.

- Learning about the socio-economic situation of the patient.

- Identifying barriers to adherence.

This has been discussed in detail in Module 2. All information is to be recorded in the patient adherence management charts.

\section{b. Patient preparation for treatment readiness}

Step 1: Introduction to the treatment and adherence program Describe the treatment and adherence program.

Discuss the layout of the health facility including the laboratory and pharmacy.

Discuss the system for treatment and follow-up:

- Three counseling sessions prior to starting ART.

- After starting ART the first two follow-up visits to be every two weeks followed by monthly doctor consultations.

- Laboratory tests. Some tests to be done every month, others every 2-6 months. The doctor will inform the patient about required investigations. 
- Medications to be collected from the pharmacy after meeting both counselor and physician. Monthly supply of drugs will be dispensed. The patient must bring all medications with him/her at time of hospital visit.

Discuss payment issues for antiretroviral medications and laboratory investigations.

Introduce staff (nurses, community health workers) who will be involved in patient care.

\section{Step 2: Discuss patient's health status}

\section{i. Overall health}

The counselor should assess the physical and mental health status.

- Is the patient able to conduct routine daily activities-household work, cooking, shopping, visiting friends or family?

- Is the patient working?

- Is the patient able to take decisions for him/herself about treatment, where to live, what to eat, what to buy etc.?

\section{ii. Current health status}

Assess the disease stage of the patient. The treating physician will have already done this during the screening process.

Discuss past opportunistic infections and hospitalizations and what it implies in terms of disease stage and disease progression.

For example, if a patient has had cryptococcal meningitis, herpes zoster, TB and candidiasis, and was hospitalized twice in the last 8 months, this would imply advanced disease with low CD4 counts, Stage 4 disease and severe immune suppression. The patient is already in the advanced disease stage and needs treatment to prevent any further damage to the immune system. The patient may perceive his HIV disease to be severe.

\section{iii. CD4 counts}

Discuss:

- CD4 cell counts are a measure of the patient's immune status, that is, the body's ability to fight infections.

- HIV virus attacks CD4 lymphocytes and destroys them.

- Normal CD4 counts should be between 600-1200 cells.

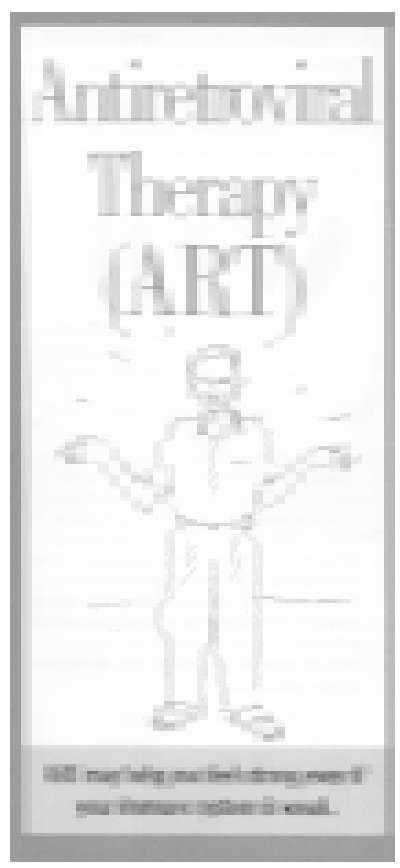

(FHI/IMPACT 2003) 
- Lower CD4 counts signify advanced HIV disease and more opportunistic infections. Severe opportunistic infections occur when CD4 cell counts decrease to below 200 cells.

- There is good news! CD4 cell counts increase with treatment and the body can once again start fighting off infections.

- In order to increase CD4 cell counts patients need to take their treatment correctly and regularly for the rest of their lives.

\section{iv. Viral load tests}

Discuss viral load tests when available and what VL implies in terms of progression to AIDS. Discuss the following points:

While it is
important to
provide accurate
information
about CD4
counts and
disease stage,
care must be
taken not to
scare or
discourage the
patient

- Viral load measures the amount of HIV in the blood.

- VL tests are very expensive and may not be available. Treatment can be done successfully without using viral load testing.

- In general, higher viral loads are associated with lower CD4 cell counts.

- Viral load decreases with ART.

- In order to achieve a decrease and maintain lower VL, patients need to take their treatment correctly and regularly for the rest of their lives.

- Higher viral load levels signify increased risk of transmitting infection.

- Persons with higher viral loads can transmit infection more easily to their partners through sex, through shared needles and through blood and blood products.

- A woman with higher viral loads can transmit infection more easily to her unborn child in the womb, at the time of delivery and through breast-feeding.

v. What can the patient expect to see with treatment?

Discuss that when treatment is taken correctly and regularly:

- The virus is controlled.

- Fewer CD4 cells are destroyed; as a result the CD4 cell count rises.

- The immune system becomes strong enough to fight infections so patients have fewer or no new opportunistic infections.

- Patients feel better and stronger with an increase in body weight.

- As the immune system improves, disease progress is prevented.

- Treatment also reduces the chance of spreading infection.

\section{vi. The importance of adherence to treatment}

The importance of adherence to treatment and the consequences of nonadherence. Discuss:

- In order to control the virus you must take all your medications on time every day over the long term-for the rest of your life. 
- If medications are not taken properly, missed or stopped in between:

- Medications stop working and are no longer effective;

- The virus can become resistant to these medications;

- CD4 counts start dropping and the viral load starts rising;

- Patients feel sick and lose weight;

- Old opportunistic infections can be reactivated or new infections occur;

- Patients need newer medications that are not available and are very expensive;

- Patients can spread resistant infections to partners.

Use patient literacy materials on ARVs.

\section{vii. Importance of protective and preventive behaviour}

It is extremely important to continue practicing safe sex (use condoms) because:

- Patients with HIV infection can still become infected with a new strain (type) of HIV virus. This is called 're-infection'.

- The new virus can worsen their disease and hasten disease progress.

- Patients can also transmit resistant infections to their partners.

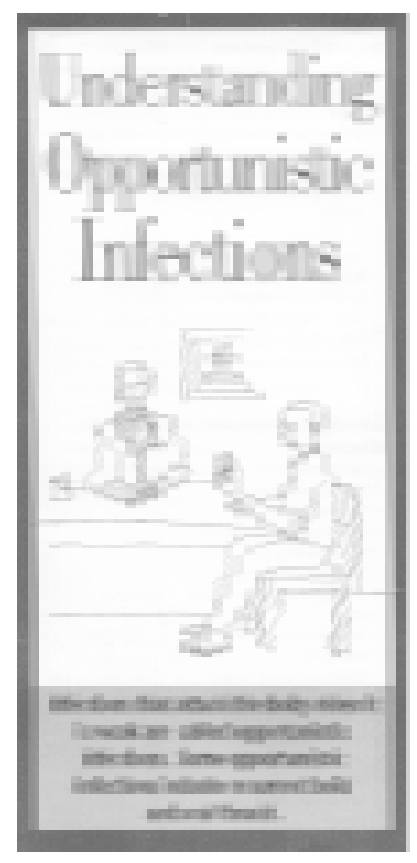

(FHI/IMPACT 2003)

- Patients with advanced disease and higher viral loads can transmit infection more easily.

- Using condoms is very important to prevent transmission of infection to others and to protect oneself from getting infected with a new strain of HIV virus.

\section{viii. Pregnancy and use of oral contraceptives}

It is important to ask lady patients about family planning methods they use and about the possibility of being pregnant or planning a pregnancy.

Oral contraceptives interfere with the metabolism of certain antiretroviral medications and may require a change in family planning method or the antiretroviral medication used. For example, patients would need to use alternative family planning methods with Lopinavir, Amprenavir, and Ritonavir etc.

Intra-uterine devices such as the Copper T or Lippes Loop may increase the chance of pelvic infections as well as transmission of HIV infection.

For patients who are pregnant or planning a pregnancy, medications like EFV cannot be used due to risk of fetal malformations. Treatment regimen for these patients should include AZT and NVP, which have been tried and tested for prevention of mother-to-child transmission of infection. Patients would need additional counseling on prevention of mother to child transmission of HIV infection and services available. 


\section{Step 3: Review patient living and work conditions}

- Employment and work routine: To identify barriers to taking medications regularly.

- Daily routine - eating and sleeping pattern: To identify ways to integrate treatment into the daily routine without much disruption.

- Access to food and income: Patients need good nutritional intake to fight the HIV disease. Patients without income, access to food, the means to meet their basic needs, would require additional support, such as linking with food donation services or income generation activities etc.

- Travel routine: Patients who travel for work (migrant workers) or for other reasons would need to prepare to take adequate supplies of medications.

- HIV confidentiality issues at place of work and at home: These influence regular intake of medications. Patients may not be able to take medications in the presence of family or colleagues. Patients may not be able to store medications suitably if they need to hide them.

\section{Step 4: Establish a treatment plan}

Discuss the treatment regimen.

- Medications: Discuss the number of ARV medications, the names and dose of medications, show the patient demonstration pills and ask the patient to repeat the names and doses.

For example, 'You have to take three ARV medications: Zerit $40 \mathrm{mg}$, one capsule two times a day, Epivir $150 \mathrm{mg}$, also one tablet two times a day and Stocrin $600 \mathrm{mg}$, one capsule once a day at night before sleeping. Please could you repeat what I just told you?'

- Dosing: Number of doses and time intervals.

- Instructions on food and fluid intake/restrictions.

For example, 'You should take Zerit by mouth with a glass of water in the morning at 8 am and in the evening at $8 \mathrm{pm}$. You may take this medication with or without food.'

- General instructions should include:

a. These medications are meant only for you. Do not share them with others. If you share them, neither of you will benefit.

b. Take all doses on time so that the medicine can have its full effect and the virus is controlled.

c. Continue to take these medications, even when you feel better. These medications do not remove the virus from the body. They can only control the virus. Therefore you need to take these or similar medications for the rest of your life.

d. If you do not take them exactly as prescribed or miss doses, the medicines may stop working and the virus may become resistant. You will then need to take new medications, which may not be available. 


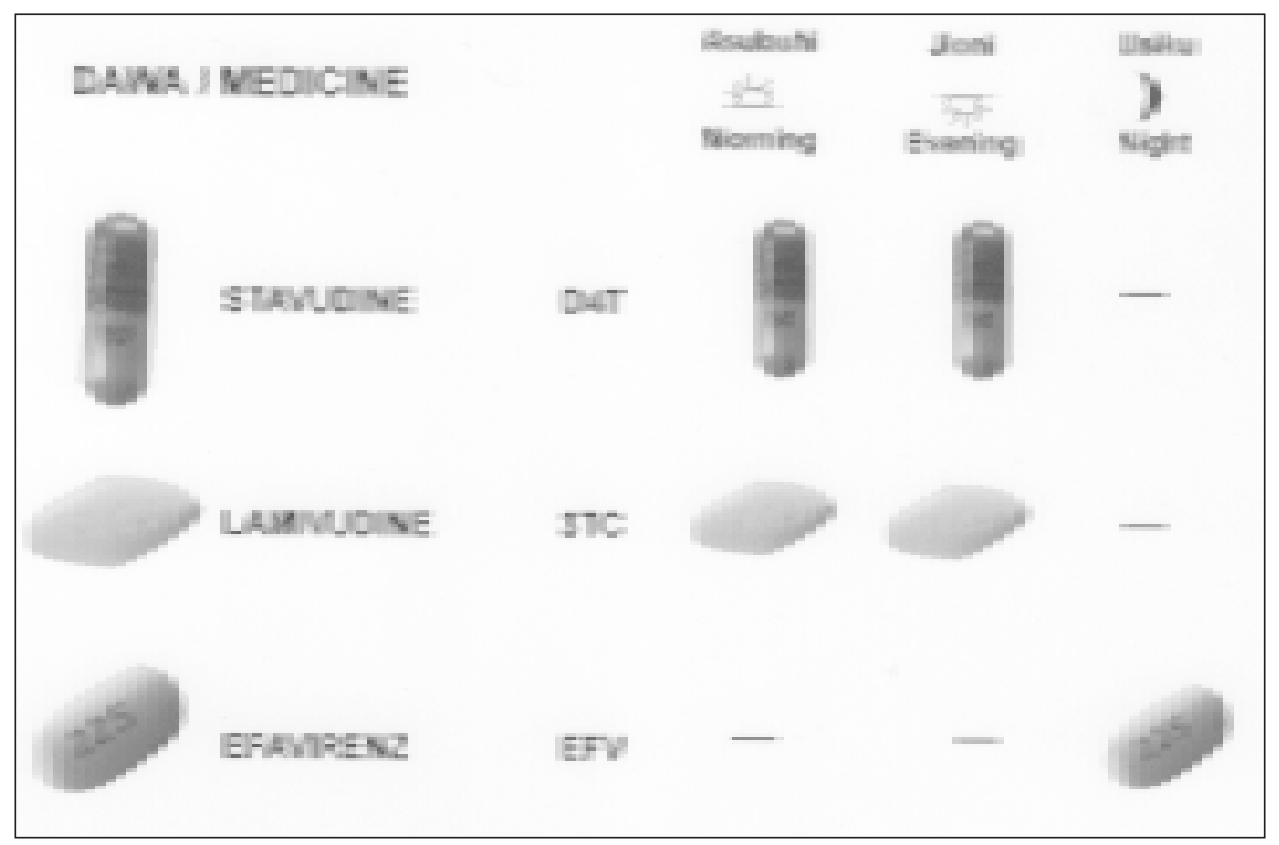

Fig. 3.1: Pill demonstration chart

- Storage of medications. Patients should be advised on how to store medications.

a. Keep these medications in a cool, dry and dark place-like a drawer or cupboard. Do not keep them near the kitchen sink or in the bathroom.

b. Heat and humidity can spoil the medications.

Side effects: These need to be briefly touched upon during this session. Too much information during the first counseling session will overwhelm the patient and may negatively influence commitment to start treatment.

\section{Discuss the follow-up plan}

- Clinic visits. Discuss the follow-up plan.

- Frequency of visits to clinic-for example first four visits after starting ART to be every two weeks, then once every month.

- Where the patient needs to report during clinic visits-for example at the reception counter of the health facility.

- How to fix new appointments or change appointments if s/he cannot come for a scheduled visit.

- Counseling sessions. Inform the patient about the next two counseling sessions. Inform that they are free to discuss their problems, concerns or doubts about medications. Counseling is an opportunity for patients to learn about their treatment and ask questions. 
- Pharmacy refill. Discuss the pharmacy refill procedure and location of the pharmacy. Inform the patient that s/he needs to meet the counselor and the doctor before proceeding to the pharmacy.

- Laboratory monitoring. Discuss the need for laboratory monitoring, process for lab investigations as advised by the doctor and locations of the laboratories.

It may be useful to ask for a rapid follow-up session 48-72 hours after the patient starts therapy to assess understanding of medication schedule and dose.

\section{Step 5: Discuss the proposed adherence strategy}

Discuss the adherence promoting strategies to be used for the patient: calendar based pill diary, treatment reminder cues, modified DOT, buddy system etc.

\section{Step 6: Identifying barriers to adherence}

The treatment preparation process should ensure that potential or actual barriers are identified. During discussions with the patient, identify potential barriers. The patient and provider can work together to address these barriers at the patient level, while the health system can address the barriers at the service delivery level.

Barriers and ways to address them have been discussed in detail in Module 2.

Step 7: Fix a date for the next appointment.

\section{Note:}

- Avoid information overload. Patients may not be able to assimilate too many details in the first session.

- Use simple language and terms. 


\subsection{Preparatory Counseling Session 2: Continued Treatment and Adherence Counseling}

\section{Step 1: Review and assess patient's understanding of his/her HIV disease stage and related treatment issues}

(a) Current health status:

(i) Disease stage: Past opportunistic infections and what that implies in terms of disease progression.

Does the patient understand his/her disease? The aim is not to depress the patient further but for them to see it as an opportunity to reverse the illness and slow disease progress.

(ii) CD4 counts: Does the patient understand what his/her CD4 count means and what it implies in terms of disease progression?

(iii) Viral load (if available): Does the patient understand what his/her viral load means, if it was done, and what it implies in terms of disease progression?

(b) What results can the patient expect to see with treatment? Review patient knowledge. Emphasize the connection between regular and correct treatment taking with effectiveness of medication, improving immune function, higher CD4 counts, lower viral load readings, fewer opportunistic infections and slowed progression to AIDS.

(c) The importance of adherence to treatment and the consequences of nonadherence.

Use patient literacy material on ARVs.

Note:

1. The approach should be of a continuing discussion on issues related to treatment.

2. Repeat information wherever necessary.

3. Re-emphasize key messages.

4. Discussion should be done in a non-judgmental way and should not appear to be an inquiry or evaluation of knowledge. 


\section{Step 2: Review and assess patient's understanding and recall of the treatment plan}

(a) Review the treatment regimen.

- Medications

- Dosing

- Instructions on food and fluid intake

- Storage of medications.

(b) Use dummy pills to repeat instructions for the patient.

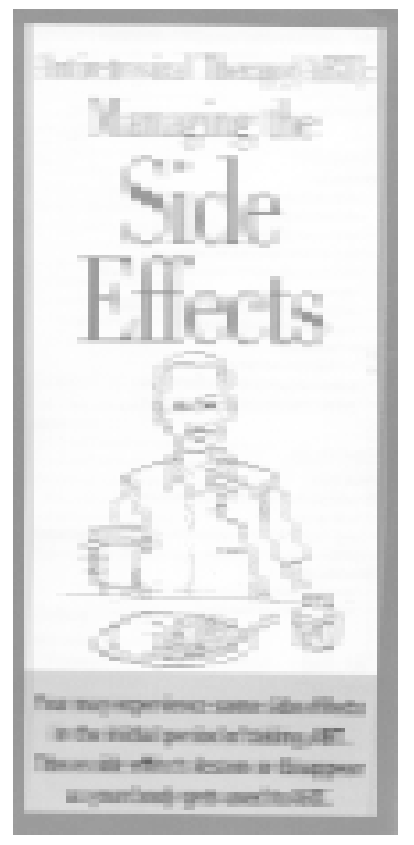

(FHI/IMPACT 2003)

\section{Step 3: Review plan for treatment follow-up}

(a) Discuss potential side effects and plan for a response.

Provide greater details on this topic in this session. This should be done in collaboration with the treating physician. Discuss:

- What side effects to expect in the short-term;

- How to manage side effects if and when they occur;

- When to seek care-danger signs to watch out for;

- Who to contact - where to go for management of side effects, names of health workers to contact.

Use patient literacy material on side effects.

(b) Discuss the plan for routine follow-up.

Plan for follow-up visits: every two weeks for the first four visits and then a monthly follow-up.

(c) Establish a contact system.

Patients should have clear instructions on how and where they can contact the provider in case of need: medication side effects, illness etc.

- Note patient's detailed address including nearby landmarks so that patient can be contacted if required (in case of missed appointments).

- Patient's contact telephone numbers should be taken.

- Nurse counselor's telephone contact number should be provided to the patient.

- Set time, location and contact plan with the patient.

(d) Help patient set goals.

All patients may not have the ability to take medications on time and regularly. Setting goals for adherence helps treatment-naïve patients to start treatment with commitment and helps treatment-experienced patients to improve treatment taking and adherence. 
Setting short-term goals (for the next 1-2 weeks) for medication intake. For example, the patient aims to achieve $100 \%$ medication intake over the next 1-2 weeks. This allows the patient to set an achievable goal, build confidence and helps the patient to commit him or herself to a treatment and adherence plan.

Setting long-term goals (for the next 6 months or year) for health outcomes may help patients take a long-term view of their treatment plan and resulting successful health outcomes. For example, take medications to achieve $10 \%$ weight gain, or to increase CD4 cell counts, or to prevent new opportunistic infections over the next 6 or 12 months.

Discuss treatment reminder 'cues' such as linking medication intake to meal time or leaving for work, placing notes at strategic points at home or office, keeping medications at visible locations at home etc.

\section{(e) Integrate treatment into patient's daily routine of activities.}

To be effective, ARV medications have to be taken on time, regularly and over the long term. This could be a lifestyle change for patients. A discussion on integrating medication intake with the patient's daily routine is extremely important — this serves to establish a participatory approach to planning and helps patients take their medications on time and regularly.

Review the patient's daily routine and the plan to integrate treatment into the daily routine. For example:

\section{Patient G K}

Morning dose of D4T and 3TC at 8 am just after breakfast before leaving for university.

Evening dose of D4T and 3TC at 8 pm after dinner.

EFV to be taken between 10-11 pm, before going to bed.

D4T and 3TC to be kept near the dining area and EFV on bedside table.

\section{Step 3: Discuss the proposed adherence strategy}

The counselor should discuss the adherence promoting strategy to be used for the client. The use of the pill diary and treatment reminder 'cues' should be discussed as part of the treatment plan. Patients should be encouraged to involve family members in helping them to adhere to the treatment.

\section{Step 4: Review barriers to adherence}

Review barriers to adherence identified during the first preparatory visit. Assess if those barriers require further counseling or intervention. Review progress made.

\section{Step 5: Fix a date for the next appointment}

Ensure that the
patient
receives the
same message
on treatment
and adherence
from all
providers -
physicians,
nurse
counselors and
pharmacists.




\subsection{Preparatory Session 3: Assessment of Patient Readiness and Initiation of ART}

To be properly prepared to start ART, patients generally require 2-3 meetings with the adherence counselor. Some patients may need more than three couseling sesstions. At the third counseling visit the treating physician and nurse counselor should assess patient readiness to initiate treatment. Patients who appear to be ready and committed can start therapy.

\section{Step 1: Review the treatment and follow-up plan in detail}

(a) Review the treatment regimen.

- Medications

- Dosing

- Instructions on food and fluid intake

- Storage of medications

- Use dummy pills to repeat instructions for the patient.

(b) Discuss potential side effects and plan for a response.

- Which side effects the patient can expect to see

- How to manage them

- When to seek care

- Where to go.

(c) Discuss the follow-up plan for routine follow-up.

- Physician follow-up visits

- Laboratory work

- Medication refill

- Counseling sessions.

(d) Discuss the adherence strategy.

- Routine monthly visits for follow-up

- Pill diary/pill box/treatment buddy/family support etc.

- Medication refills_pharmacy appointments

- Missed appointments, contact plan, and home-tracing plans.

(e) Review contact system.

(f) Review patient goals for his/her health.

- Short-term goals for medication intake

- Long-term goals for health outcomes. 


\section{Step 2: Assessment of patient-treatment readiness}

It may be best to initiate treatment once the patient demonstrates an understanding of the disease, of the treatment and the link between adhering to treatment and successful treatment outcomes (such as improved immune status, increasing CD4 counts, decreasing viral load etc.) and when the patient is able to make some commitment towards long-term treatment and adherence to treatment.

- Does the patient know his treatment regimen? Does s/he understand dosing and dietary instructions?

- Does the patient demonstrate an understanding of his disease?

- HIV infection and disease stage

- Treatment is not a cure

- CD4 count - patient level and what it implies, expected change with successful treatment

- Viral load.

- Does the patient understand the link between good adherence and successful treatment: improved immune status, increasing CD4 cell counts?

- Has the patient demonstrated a commitment to taking medication longterm?

- Does the patient have a major barrier and has that been addressed?

- Is the patient ready to start treatment?

The counselor and physician determine whether the patient is ready to start treatment and refer the patient to the pharmacist with a prescription.

Step 3: Refer to the pharmacy to provide ARV medications The pharmacist reviews the medications and instructions with the patient and provides medications. Pharmacists also counsel the patient on medication intake, adherence and side effects.

\section{Step 4: Set up appointment for next visit}




\section{MODULE 4 \\ Ongoing Adherence Counseling}



MODULE 4

\section{Ongoing Adherence Counseling}

\section{OBJECTIVES}

- To provide trainees with skills in ongoing adherence counseling

- To provide trainees with skills in problem solving

\section{ACTIVITIES}

1. Presentation and discussion on ongoing adherence counseling $60 \mathrm{~min}$.

2. Role play $60 \mathrm{~min}$.

3. Review or summary $15 \mathrm{~min}$.

2 hour 15 min.

\section{HANDOUTS}

1. Additional reading material on Ongoing Counselling: Module 4

2. Patient literacy materials

3. Checklist for ongoing counseling

METHODOLOGY:

Presentation with interactive discussion

MATERIALS:

Power Point

DURATION $60 \mathrm{~min}$.

\section{Activity 1: Presentation and Discussion}

The presentation will discuss problem solving with a focus on medicationrelated side effects, disease progress, illnesses, and psychosocial problems. The trainer or presenter will use this session to encourage discussion in the form of an interactive session. Participants will be encouraged to discuss problems they face when managing patients in their clinics with a focus on psychosocial problems that may pose barriers to adherence. 


\section{Ongoing Adherence Counseling}

\section{(1) Pyulainchanall}
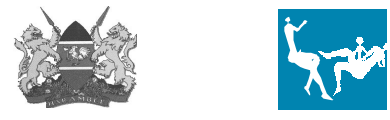

Hgrizons

\section{Training Objectives}

At the end of this session participants should have a basic understanding of

$>$ Problem solving

> Addressing side effects

> Assessing and supporting adherence

\section{Ongoing Adherence Counseling}

Challenges:

> Barriers change over time

$>$ Multiple factors influence adherence at any time

$>$ Adherence changes over time

Although counseling needs change over time, the approach remains the same! 
Step 1: Review and assess adherence over last month

\section{$>$ Medications}

- Change in medicines or doses

- Dietary instructions

- Storage

Adherence

- Taken all doses

- Taken on time

- Reasons for missing dose

- Complete pill count and self report

Difficulties or side effects experienced

\section{Assess Adherence}

\section{Adherence from pill counts:}

\section{$\times$}

\section{Adherence from self report:}

$\%$ Adherence over last 4 days =

\# doses should have taken - \# missed doses \# doses should have taken

\begin{tabular}{|c|c|c|}
\hline Away from home & Forgot/Busy & Slept in \\
\hline Felt ill & Ran out of pills & \\
\hline \multirow[t]{2}{*}{ Felt better } & $\begin{array}{l}\text { easons for } \\
\text { ssing doses }\end{array}$ & \multirow[t]{2}{*}{ Pills do not help } \\
\hline & ear of side effects & \\
\hline $\begin{array}{l}\text { Did not want } \\
\text { others to see }\end{array}$ & $\begin{array}{l}\text { Family said no to } \\
\text { medications }\end{array}$ & $\begin{array}{c}\text { Instructions not } \\
\text { understood }\end{array}$ \\
\hline
\end{tabular}




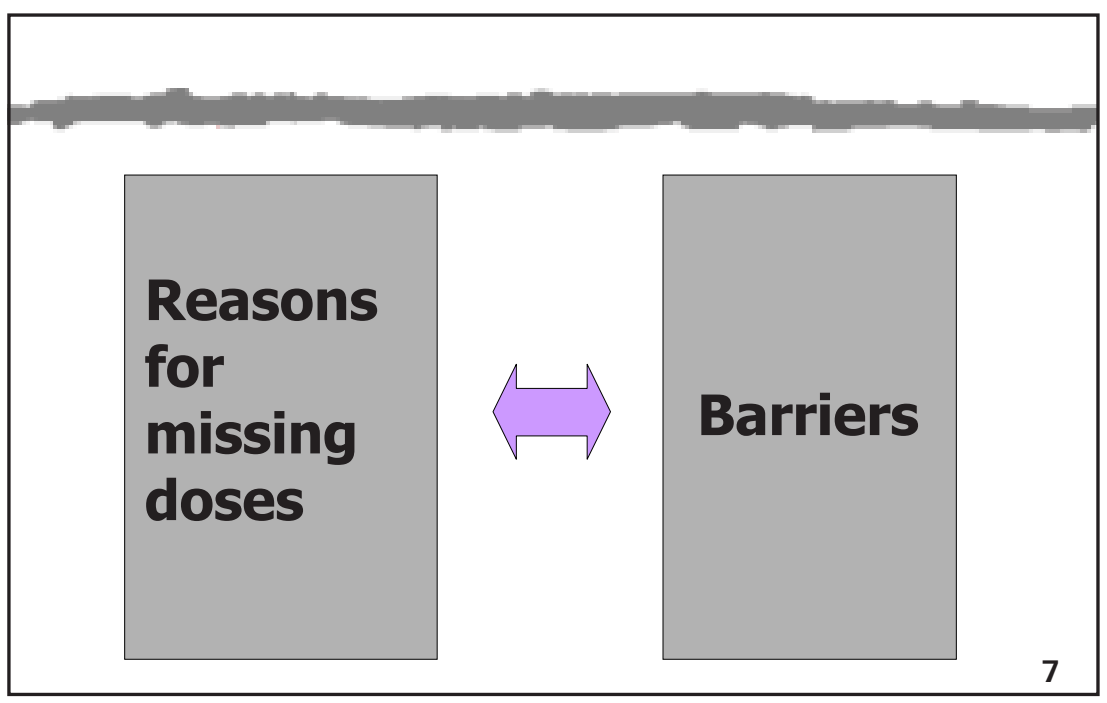

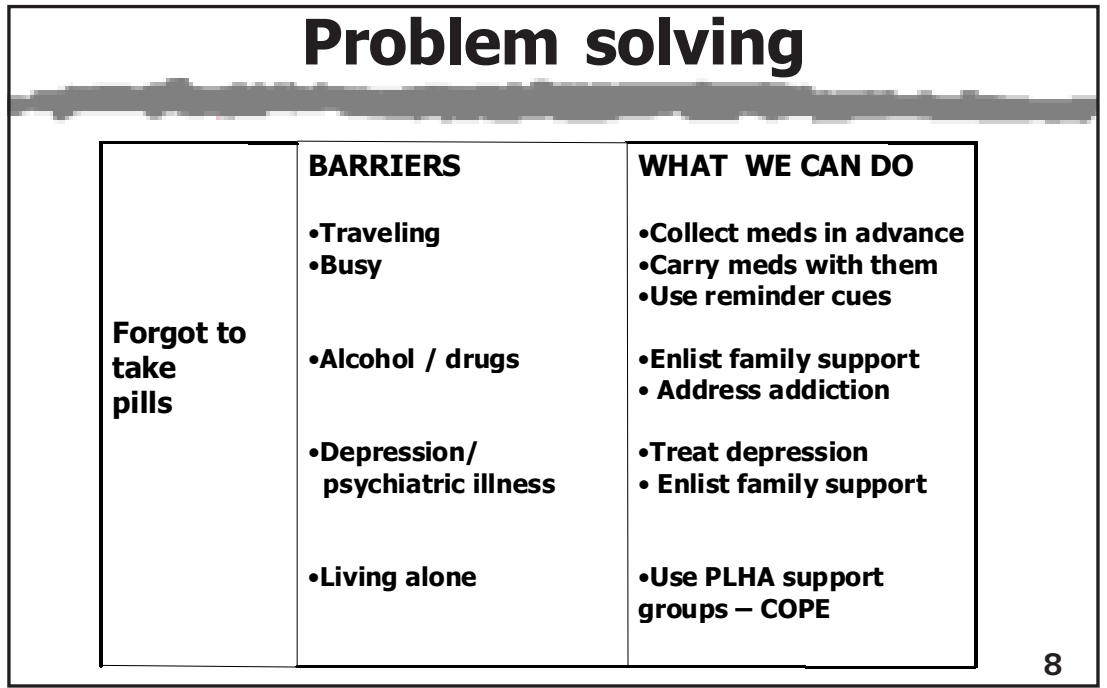

\section{Problem solving (contd)}

\begin{tabular}{|c|c|c|}
\hline $\begin{array}{l}\text {-Pills do not } \\
\text { help } \\
\text {-Felt better } \\
\text { so did not } \\
\text { continue }\end{array}$ & $\begin{array}{l}\text { BARRIERS } \\
\text {-Inadequate } \\
\text { knowledge } \\
\text { - Patient attitudes }\end{array}$ & $\begin{array}{l}\text { WHAT WE CAN DO } \\
\text {-Enhance counseling } \\
\text { •Use literacy materials } \\
\text {-Involve family } \\
\text { members }\end{array}$ \\
\hline $\begin{array}{l}\text {-Did not want } \\
\text { others to see }\end{array}$ & $\begin{array}{l}\text { - Stigma } \\
\text {-Difficulty with } \\
\text { disclosure }\end{array}$ & $\begin{array}{l}\text { - Counseling } \\
\text {-Support disclosure } \\
\text { - Keep medications } \\
\text { with friend }\end{array}$ \\
\hline
\end{tabular}




\section{Problem solving (contd)}

\begin{tabular}{|c|c|c|}
\hline $\begin{array}{c}\text { Unable to care for } \\
\text { self }\end{array}$ & $\begin{array}{l}\text { BARRIERS } \\
\text { •No employment } \\
\text { - Living alone } \\
\text { - AIDS dementia }\end{array}$ & $\begin{array}{l}\text { WHAT WE CAN DO } \\
\text {-Use PLHA support } \\
\text { groups - COPE } \\
\text {-Income generation } \\
\text { activities } \\
\text {-Food donation programs } \\
\text { - Send CHW home } \\
\text {-Family support }\end{array}$ \\
\hline $\begin{array}{l}\text { Instructions } \\
\text { not } \\
\text { understood }\end{array}$ & $\begin{array}{l}\text {-Literacy levels } \\
\text {-Depression/ } \\
\text { psychiatric illness } \\
\text {-Alcohol / drugs }\end{array}$ & $\begin{array}{l}\text {-Use literacy materials } \\
\text { - Use dummy pills } \\
\text { - Repeat instructions } \\
\text {-Enlist family support } \\
\text { - Treat depression and } \\
\text { addiction }\end{array}$ \\
\hline
\end{tabular}

\section{Ongoing Support (contd)}

\section{Missed appointments (sick, distance)}

$>$ Send tracer CHW

$>$ Reminders, Phone call

$>$ Change to nearest treatment site

\section{Missed Doses}

$>$ Do not take a double dose

$>$ Within 3 hours of scheduled dose take the missed dose

$>$ If $>3$ hours of scheduled dose, miss dose and go on to the next dose, carry on the treatment schedule

\section{Ongoing Support (contd)}

\section{Pill Fatigue}

$>$ "Drug Holidays"

$>$ Counsel, support the patient

$>$ Manage side effects

$>$ Enlist family support

\section{Side effects}

$>$ Discuss how to address them at start of ART as well as during treatment

$>$ Inform patients when to seek medical care

$>$ Use patient literacy materials 


\section{Side effects: Nausea and vomiting}

> Commonly seen with AZT, DDI and Kaletra

> Usually transient and resolves in 2-4 weeks

$>$ Refer to the physician:

$>$ If severe abdominal pain, respiratory difficulty and disorientation - may be a sign of lactic acidosis

$>$ Severe abdominal pain may also be a symptom of pancreatitis

$>$ If patient is dehydrated

> If fever, headache, disorientation, altered consciousness - may indicate meningitis and not ADR

\section{Advice to patients}

$>$ Take with food if permitted

$>$ Eat more frequent small meals

> Avoid greasy, spicy and fatty foods. Take bland lightly cooked food - rice, soups, bananas, biscuits

$>$ Drink sips of clean boiled water, weak tea, and lemon water. Maintain hydration

$>$ Contact nurse or doctor in case of fever, vomiting more than three times/day, thirsty but unable to drink, pain in abdomen, breathlessness, confusion

\section{Side effect: Headache}

Usually transient and passes over 2-4 weeks

If accompanied by fever, disorientation, altered consciousness or convulsions may indicate meningitis, encephalitis or space occupying lesion - refer patient to physician 


\section{Advice to patients}

Rest in a quiet, dark room

Place cold cloth over eyes and forehead

$>$ Avoid strong tea or coffee

> If not relieved with 4-5 doses of Paracetamol, consult health worker

$>$ If frequent and severe headaches or fever, vomiting, altered consciousness, blurred vision or convulsions contact a nurse or doctor immediately

\section{Side effects: Diarrhea}

Usually transient and passes over 2-4 weeks

Refer to the physician

$>$ If blood or mucus or fever refer to physician to treat infection

$>$ If severe diarrhea

$>$ More than 5 times per day

$>5$ or more consecutive days

$>$ Weight loss of more than $2 \mathrm{~kg}$

\section{Advice to patients}

Eat small meals more times a day

> Eat soft, easy-to-digest food - rice, bananas, biscuits. Avoid greasy, spicy and fatty foods.

Drink sips of clean boiled water, weak tea, ORS, lemon water. Avoid orange juice or very salty soups as they can increase diarrhea. Maintain hydration.

$>$ If fever, mucus or blood in stools, diarrhea more than 4-5 times a day for 5 or more days, contact nurse or doctor 


\section{Side effects: Rash}

Rashes mostly seen with NVP, EFV, Abacavir *Any new medication may cause allergic rash

Mild rash and itching can be treated with antihistamines and calamine lotion

> Severe rash (peeling of skin, watery discharge, blistering, and ulceration) requires immediate physician referral and removal of medication

\section{Advice to patients}

Keep skin clean and dry

Use mild soaps

Drink plenty of water to keep skin hydrated

Antihistamines to relieve itching and rash

> Use Calamine lotion

If peeling of skin, blistering, or ulceration contact nurse or doctor immediately

\section{Side effects: CNS Symptoms} (Nightmares, sleeplessness, sadness or worry)

> Mostly seen with EFV

> Usually transient and disappear in 2-4 weeks

$>\mathrm{EFV}$ at bedtime reduces symptoms

If severe depression, loss of interest or suicidal ideas, refer to the physician and counselor 


\section{Advice to patients}

Usually temporary and will resolve in few weeks

Take EFV at bedtime

Avoid heavy meals before sleeping

Avoid alcohol, drugs

$>$ Talk about your feelings with your friends or family

$>$ If feel very sad, have thoughts of killing yourself, contact a nurse or doctor immediately

\section{Side effects: Fatigue}

$>$ Fairly common

> Multiple causes - HIV infection, medications, depression, anemia

$>$ Regular and restful routine helps to reduce fatigue

$>$ Alcohol and use of recreational drugs worsen fatigue

\section{Advice to patients}

Avoid alcohol, tobacco, Miraa and other recreational drugs

Light physical exercise may help

Balanced diet with fruits and vegetables

Consult nurse or doctor if feel very depressed 


\section{Side effects: Numbness, tingling or burning}

> Mostly seen with D4T, DDI

> Other ARV medications and INH, Rifampicin can also cause neuropathy

$>$ If severe and associated with weakness and inability to walk - refer to the physician. Medications may need to be changed

$>$ Usually non-reversible

> Vitamin supplements and antidepressants may relieve symptoms

\section{Advice to patients}

Protect your feet

Dear loose fitting shoes and socks

$>$ Keep feet uncovered in bed

Soak feet in warm water, massage feet

Don't walk too much at a time

Inform health worker

\section{Side effects: Change in appearance}

> Lipoatrophy/Lipodystrophy - fat redistribution

$>$ Usually seen after several months treatment mostly with D4T and PIs

$>$ Usually not reversible

$>$ Limited treatment available

$>$ When associated with metabolic disturbances like e.g. hyperlipidemia or hyperglycemia, regimen may be changed

$>$ Management of diabetes and hyperlipidemia required 


\section{Other side effects}

Hepatitis, pancreatitis, renal dysfunction, anemia, metabolic disturbances like hyperglycemia or hyperlipidemia are diagnosed through laboratory tests

Refer to the clinician for management when any of the above seen

\section{Ongoing counseling}

\section{Step 2:}

Discuss the follow up plan

$>$ Review upcoming travel plans, contact information

$>$ Review patient's goals. Set new goals

Step 3:

Set up appointment for next visit 


\section{Activity 2: Group Activity: Role Play}

Participants will be asked to break up into groups. Participants will be given cases to discuss and role-play. This activity is designed to enhance counseling skills. Patients will be asked to use the ongoing counseling checklist and patient literacy material to facilitate counseling. This activity will build on earlier modules where preparation of the patient has been discussed.

\section{METHODOLOGY:}

Small Group

Discussion

MATERIALS:

Flip Chart, checklists, patient literacy material, demonstration pill chart

DURATION $60 \mathrm{~min}$. 


\section{Adherence Training Role Plays}

\section{Role Play 1}

An 18-year-old Matatu tout with symptomatic HIV infection is started on first line ART (3TC/D4T/EFV) and is being followed by Directly Administered ART (DAART) at CPGH. He has had TB and cryptococcal meningitis last year. He lives with his girlfriend in the suburbs and has just recently disclosed his HIV status to his girlfriend, so she knows about his treatment. He consumes moderate amounts of alcohol. At his 3monthly visit it is noticed that he has failed to attend DAART on two occasions in the last month. His home district is Kitui. He has been complaining of numbness and tingling in his feet.

Discuss the implications of this non-adherence and your adherencecounseling plan highlighting the issues (side effects, travel, change in routine, depression, alcohol), which should be discussed.

\section{Role Play 2}

Mwanahidi is a 40-year-old widow who lives in the Majengo slum with her four children. She is on first line therapy (3TC/D4T/EFV) and fails to come to her second routine monthly clinic visit. The community health worker visits her at home. She is unkempt and neighbours report she has become quiet, sad and withdrawn. She has not been eating anything because of nausea and vomiting. She is also complaining of pain in her abdomen. Her CD4 count was 23 cells at the time of starting ART. She has had TB and herpes zoster before starting ART.

Discuss the implications of this non-adherence and your adherencecounseling plan, highlighting the issues which should be discussed. Conduct the session.

\section{Role Play 3}

Tom is a 40-year-old barman in a city hotel. He lives alone. He started ART (3TC/D4T/EFV) seven months back. He has attended all his monthly appointments until the last two months when he has had to be traced by a community health worker. He has been drinking heavily and says he is feeling better so has stopped treatment since last month. He had been complaining of changes in his appearance, sunken cheeks and fat around his abdomen. Liver function tests show raised SGOT/PT levels.

Discuss your adherence-counseling plan highlighting issues relevant to this case. Conduct the session. 


\section{ADHERENCE COUNSELING CHECKLIST COUNSELING SESSION FOLLOW UP}

Client's name

Date of counseling session.

\begin{tabular}{|l|l|}
\hline & Review the patient's experience with treatment and adherence over the past month \\
\hline & Drug regimen and adherence-pill counts, self report \\
\hline Discuss side effects and actions taken \\
\hline Discuss need for continued prevention \\
\hline Review experience with follow-up plan \\
\hline Discuss follow-up plan for next month \\
\hline Review patient's goals and success at achieving them \\
\hline Review barriers to adherence \\
\hline Buddy reminder-discuss role of support person \\
\hline Review pill diary \\
\hline Review barriers to adherence \\
\hline Poor communication \\
\hline Low level of literacy \\
\hline Inadequate understanding of HIV/AIDS \\
\hline Lack of social support \\
\hline Failure to disclose status \\
\hline Alcohol and drug use \\
\hline Mental state \\
\hline Fill ART register, schedule next appointment and complete appointment card \\
\hline Refer to Pharmacy \\
\hline
\end{tabular}

\section{Activity 3: Review. $Q$ and $A$.}

Ask two volunteers to come up and present main points for the day. Allow trainees to ask questions, seek clarifications or additional information. Give out the additional reading material. Encourage trainees to read material and discuss issues the next morning.

METHODOLOGY:

Volunteer Discussion

MATERIALS:

Flip Chart, Additional Reading Material

DURATION $15 \mathrm{~min}$. 


\section{ADDITIONAL READING MATERIAL}

\section{FOLLOW-UP COUNSELING AND ONGOING SUPPORT}

Adherence levels change over time as patients get accustomed to their treatment, face new challenges, experience side effects or feel better. Counseling needs to change as well over time. Different patients require a different level of ongoing support, necessitating a patient-centered individualized approach.

In resource-constrained settings with staffing shortage, providing ongoing support and follow-up counseling may not be possible for all patients. Counselors need to be aware of potential barriers a patient may face and be available to provide support when necessary. Ongoing counseling may be reserved for the most vulnerable clients and needs to be patient-centered and individualized.

\subsection{Follow-Up Counseling Session}

\section{Adherence changes over time}

Barriers change over time

\section{Step 1: Review and assess the patient's experience with} treatment and adherence over the past month

(a) Review the treatment regimen.

- Review medication names and any change in treatment regimen.

- Dosing instructions-during the early follow-up period or if new medication has been added.

- Instructions on food and fluid intake-during the early follow-up period or if new medication has been added.

- Storage of medications-during the early follow-up period or if new medication has been added.

(b) Discuss adherence.

- Discuss medications taken.

- Complete pill count and self-report. Assess adherence (Box overleaf).

- Determine reasons for missed doses. Discuss ways to address problem areas.

(c) Discuss side effects experienced and actions taken.

- Discuss side effects experienced since last visit and how patient addressed those. 


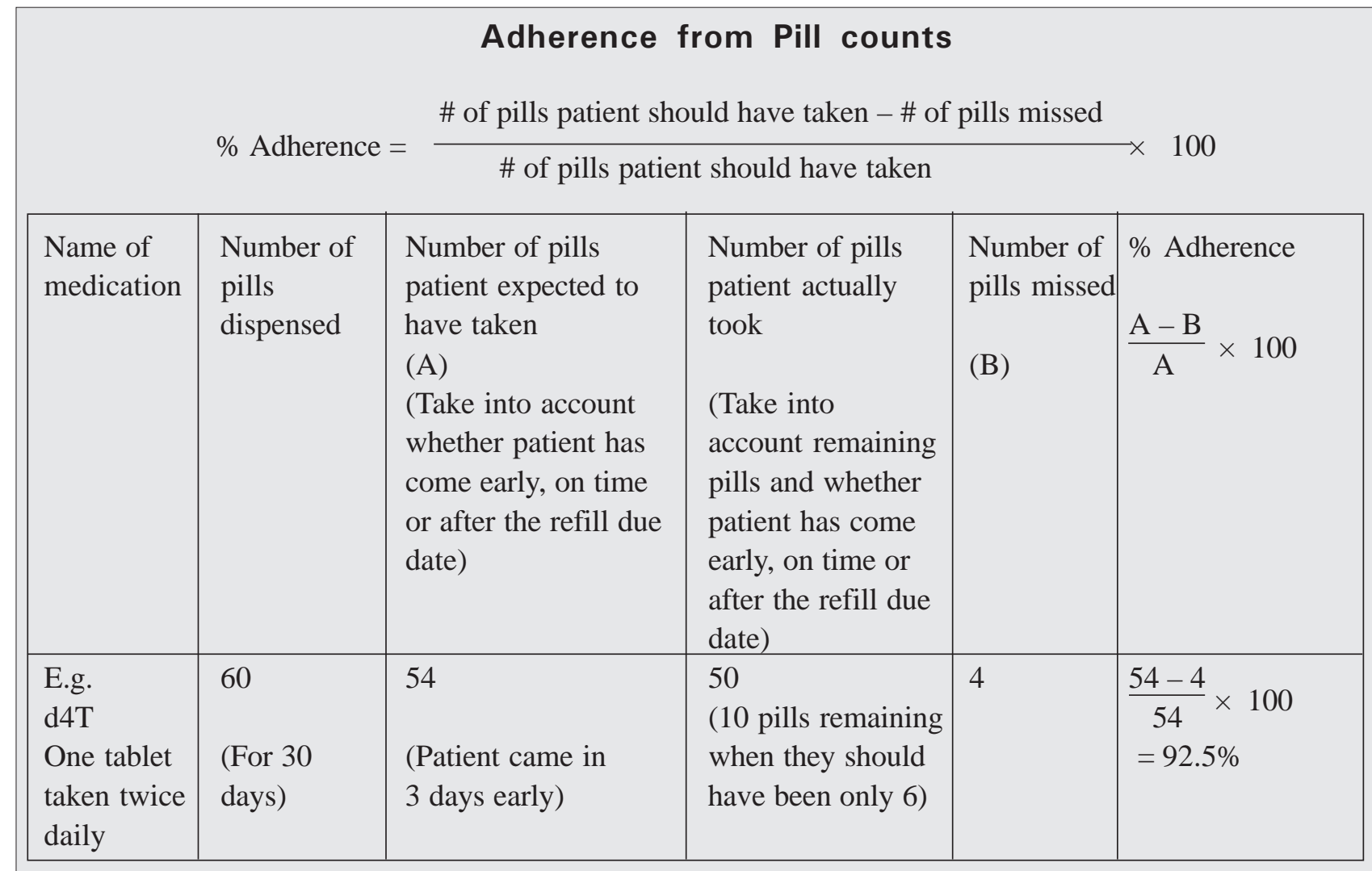

Adherence could be $<100 \%$ when patients have taken fewer pills than required or $>100 \%$ when they have taken extra pills by mistake.

\section{Adherence from Self-Report}

Adherence measured using a self-report will only reflect the adherence over the period of recall; e.g. 3 days in the table below.

Patients should be asked about missed doses: How many doses of d4T did you miss - yesterday, the day before that and the day before that ( 3 days ago)?

$$
\% \text { Adherence }=\frac{\# \text { of doses patient should have taken }-\# \text { of doses missed }}{\# \text { of doses patient should have taken }} \times 100
$$

\begin{tabular}{|l|l|l|l|l|}
\hline $\begin{array}{l}\text { Names of } \\
\text { Medications }\end{array}$ & Yesterday & $\begin{array}{l}\text { Day before } \\
\text { yesterday } \\
\text { (Missed doses) }\end{array}$ & $\begin{array}{l}\text { The day before } \\
\text { that (3 days back) } \\
\text { (Missed doses) }\end{array}$ & $\%$ Adherence \\
\hline $\begin{array}{l}\text { E.g. d4T } \\
\begin{array}{l}\text { One tablet } \\
\text { taken twice } \\
\text { daily }\end{array}\end{array}$ & 0 & 1 & 1 & $\frac{6-2}{6} \times 100=67 \%$ \\
\hline
\end{tabular}

A DHERENCE TO A N TIRETROVIR A L THER A P Y IN A D U L T S : A G U D E FOR TRAINER 
- Advise patient on how to manage short-term and mild side effects. For serious side effects refer to the physician. (Discussed in detail later in this module.)

- In collaboration with the physician, set up ways to address side effects. Identify problem areas.

- Review when to seek care, how to contact providers.

(d) Review the experience with the follow-up plan.

- Problems faced with the follow-up plan. For example, the patient is unable to attend clinic on scheduled days because of travel upcountry, working overtime so could not collect medications etc.

- Develop new strategies to address problem areas and barriers.

(e) Discuss the follow-up plan for routine follow-up.

- Enquire about any proposed travel— the patient should inform in advance and collect extra supply of medications prior to travel.

- Enquire about any change in life conditions: change in address, financial problems, separation or divorce, pregnancy, new child, death of a loved one, etc. Do not ask specifically about each one, allow the patient to tell you. Probe.

- Review contact information.

(f) Review patient goals and patient's success with achieving them.

- Was the patient able to achieve his goals?

- What to do to achieve them next time?

- Set new goals. For example, over the next two weeks the patient will try to get up early and take all his medications within 2 hours of the due time; will use an alarm clock.

- Integrate treatment into the patient's daily routine of activities.

(g) Review barriers to adherence.

Review the barriers to adherence identified earlier and new barriers that have come up and success in addressing them. These may change during the course of treatment - the patient may start drinking, may be thrown out of home, may face economic loss, loss of employment, travel and movement etc. Problem solving is discussed later in this module.

\section{Step 2: Complete the required data collection forms}

\section{Step 3: Set up appointment for next visit}

Multiple factors
influence
adherence at
any time
A patient-
centered
individualized
approach is
necessary




\subsection{Ongoing Support}

\section{a. Practical problem solving}

Patients may not take their medications for several reasons. Problem solving relates to finding out the cause for missing medications and addressing those reasons/barriers. The table below lists some of the common reasons patients cite for missing doses, possible barriers and suggestions on problem solving.

\begin{tabular}{|c|c|c|}
\hline $\begin{array}{l}\text { Reasons for missing } \\
\text { doses given by } \\
\text { patients }\end{array}$ & Possible barriers & Problem solving \\
\hline Forgot to take pills & $\begin{array}{l}\text { Patient forgot because: } \\
\text { - Traveling } \\
\text { - Alcohol/active drug use } \\
\text { - Depression/psychiatric } \\
\text { illness } \\
\text { - Living alone and sick } \\
\text { - Homeless, no family } \\
\text { support }\end{array}$ & $\begin{array}{l}\text { - Plan before travel, take } \\
\text { extra pills } \\
\text { - Use reminder cues } \\
\text { - Address addiction } \\
\text { (alcohol and drugs) } \\
\text { - Enlist family support } \\
\text { - Treat depression } \\
\text { - Use PLHA support } \\
\text { groups }\end{array}$ \\
\hline $\begin{array}{l}\text { Pills do not help } \\
\text { Felt better so did } \\
\text { not continue }\end{array}$ & $\begin{array}{l}\text { - Inadequate knowledge } \\
\text { - Incorrect beliefs and } \\
\text { attitudes }\end{array}$ & $\begin{array}{l}\text { - Enhanced counseling } \\
\text { - Provide scientific } \\
\text { information and } \\
\text { examples } \\
\text { - Enlist family support }\end{array}$ \\
\hline $\begin{array}{l}\text { Family said no to } \\
\text { medications }\end{array}$ & $\begin{array}{l}\text { - Inadequate knowledge } \\
\text { - Incorrect beliefs and } \\
\text { attitudes }\end{array}$ & $\begin{array}{l}\text { - Family counseling } \\
\text { - Provide scientific } \\
\text { information and } \\
\text { examples }\end{array}$ \\
\hline $\begin{array}{l}\text { Instructions were } \\
\text { not clear } \\
\text { Did not understand } \\
\text { how to take } \\
\text { medications }\end{array}$ & $\begin{array}{l}\text { - Literacy levels } \\
\text { - Depression/psychiatric } \\
\text { illness } \\
\text { - Alcohol/active drug use } \\
\text { - Insufficient time to } \\
\text { counsel }\end{array}$ & $\begin{array}{l}\text { - Use literacy materials } \\
\text { - Use dummy pills and } \\
\text { repeat instructions } \\
\text { - Ask patient to repeat } \\
\text { instructions } \\
\text { - Enlist family support } \\
\text { - Treat depression } \\
\text { - Address addiction } \\
\text { (alcohol and drugs) }\end{array}$ \\
\hline
\end{tabular}

(Contd.) 
Table Continued.

\begin{tabular}{|c|c|c|}
\hline $\begin{array}{l}\text { Reasons for missing } \\
\text { doses given by } \\
\text { patients }\end{array}$ & Possible barriers & Problem solving \\
\hline $\begin{array}{l}\text { Unable to care for } \\
\text { self }\end{array}$ & $\begin{array}{l}\text { - Living alone } \\
\text { - No employment } \\
\text { - AIDS dementia/mental } \\
\text { illness }\end{array}$ & $\begin{array}{l}\text { - Use PLHA support } \\
\text { groups } \\
\text { - Register with the } \\
\text { home-based care } \\
\text { program } \\
\text { - Link with FBO } \\
\text { food donation } \\
\text { programs } \\
\text { - Locate family and } \\
\text { enlist support } \\
\text { - Identify a friend who } \\
\text { could help }\end{array}$ \\
\hline $\begin{array}{l}\text { Did not want others } \\
\text { to see patient taking } \\
\text { medications }\end{array}$ & $\begin{array}{l}\text { - Stigma at place of work } \\
\text { - Non-disclosure in the } \\
\text { family }\end{array}$ & $\begin{array}{l}\text { Provide counseling } \\
\text { support to help with } \\
\text { disclosure } \\
\text { - Identify a friend who } \\
\text { could help keep } \\
\text { medications }\end{array}$ \\
\hline Fear of toxicity & $\begin{array}{l}\text { - Insufficient preparation } \\
\text { - Inadequate knowledge }\end{array}$ & $\begin{array}{l}\text { - Provide scientific } \\
\text { information on what } \\
\text { to expect and how to } \\
\text { manage it } \\
\text { - Counsel on risks of } \\
\text { non-adherence }\end{array}$ \\
\hline
\end{tabular}

\section{b. Missed appointments}

Patients may miss appointments for several reasons ranging from travel outside their place of residence, being busy with other things, forgetting, employment, confidentiality issues, distance from the health center, economic problems or being too sick and unable to travel.

- Identify barriers and ways to address them. Patient participation may be necessary to ensure continuing medication intake and adherence to treatment. 
- Provide additional counseling support.

- Establish a system of 'tracers' or a way to contact patients at home to prevent non-adherence with chronic defaulters.

- Adapt the service delivery system to overcome systemic barriers - a clientfriendly clinic, flexible hours, 'one-stop shop' (that is adjusting appointments so that patients could complete all required appointments with physician, counselor, social worker, psychiatrist, dermatologist, neurologist as required during the same hospital visit).

- Setting goals to not miss appointments.

- Planning before travel so that the patient can take an extra supply of medications with him/herself.

\section{c. Missed doses}

Reasons for missing doses may vary from simply forgetting, travel, work hours, running out of pills, sharing medications, being unable to get to the clinic, not understanding instructions, feeling better, family pressure not to take medications etc. Most of these reasons are linked to barriers that the patient faces. Identifying and addressing barriers has been discussed in Module 2.

Patients can be given the following advice:

- Do not to take two doses at one time.

- Do not take the missed dose close to the time of the next dose.

- Take the missed dose if within 3 hours of the scheduled time.

- Drop the missed dose and take the next dose on time if after 3 hours of scheduled dose time. Carry on with the treatment schedule. Mark the pill diary for the missed dose with the reason for missing medication.

- If severe side effects occur, inform the physician or adherence counselor or health worker.

\section{d. Reminders}

When follow-up visits are far apart, patients may need to be reminded about the clinic appointments. This could be done through the local community health worker network, sending letters or appointment cards, using family members to keep track of clinic appointment or through phone calls.

\section{e. Medication regimen related problems}

Patients may find themselves unable to cope with some of the side effects related to medication intake, burden of pills to be taken, complicated 
instructions etc. In some cases physicians may be able to change the regimen to include preparations that contain two or three medications in a single pill (fixed dose combinations) thus reducing the number of pills to be taken. With newer preparations coming into the market, once-a-day dosing could also be considered. This is best done at the start of treatment.

In resource-constrained settings the choice of drugs is often limited and this may not be possible.

\section{f. 'Pill fatigue' and 'drug holidays'}

Patients who have been on treatment for a some time may experience problems related to taking a large number of pills. They may get tired of taking medications every day or feel overwhelmed-'pill fatigue'. In western countries patients have been known to take 'drug holidays' - that is stop taking medications for a few days, e.g., weekends or during holiday travel. While this may not be seen yet among patients in developing country programs it is useful to keep it in mind when following-up patients on ART. This should be discouraged!

\section{g. Side effects}

These may range from short-term side effects to more delayed long-term effects. Short-term side effects generally disappear over 2-6 weeks. Patients should be supported through this period and encouraged to continue. Family support and sometimes peer group support (where patients are willing to disclose/share status) may be helpful. Setting short-term goals also helps patients to keep taking medications.

Management of long-term side effects or adverse events is to be done by the treating physician; nurse counselors should refer the patient to the treating physician. Physicians may need to change the ARV medication or prescribe specific treatment such as oral hypoglycemics or insulin for diabetes, lipidlowering medications for hyperlipidemia. Future management should be done in collaboration with the physician.

\section{(i) Nausea and vomiting}

- Nausea and vomiting are commonly seen with NRTIs: AZT, DDI and with Protease inhibitors: Kaletra, Crixivan, Ritonavir, Saquinavir etc. Nausea and vomiting can also be seen with any new medication that a patient may take. Nausea and vomiting associated with ART is usually temporary and passes in 2-6 weeks. Patients should be supported during this period till the symptoms abate. 
- The patient should be asked to consult the physician or nurse if vomiting is accompanied by severe abdominal pain, respiratory difficulty and disorientation, as the patient may be suffering from lactic acidosis.

- Severe abdominal pain could also be a sign of pancreatitis.

- In the case of severe vomiting, more than 5-6 times for more than one day, the patient may develop dehydration (dry tongue, loose skin, listlessness, thirst, not passing urine), and should consult the physician or nurse.

- If vomiting is accompanied by fever, headache, disorientation, or altered consciousness, patients should be advised to consult the physician or nurse as they may be suffering from other conditions such as meningitis, encephalitis, lymphoma or toxoplasmosis.

The patient can be given the following advice:

- Follow doctor's instructions; ask if medications can be taken with food.

- Eat more frequent small meals.

- Avoid greasy, spicy and fatty foods. Take bland, lightly cooked foodrice, soups, bananas, biscuits.

- Drink sips of clean boiled water, weak tea, and lemon water. Maintain adequate hydration.

- Contact nurse or doctor in case of fever or blood in vomit, if vomiting continues for more than one day, thirsty but unable to drink, not passing urine, disoriented or unconscious.

\section{(ii) Headache}

Headache is most commonly seen with AZT, 3TC, d4T, DDI, Crixivan, Saquinavir and NVP. Headache can also be seen with any new medication. It is usually transient and passes over 2-6 weeks as the body gets used to the new medications. If headache is accompanied by fever, disorientation, altered consciousness or convulsions it may indicate meningitis, encephalitis, lymphoma or toxoplasmosis and requires immediate consultation with the physician.

The patient can be given the following advice:

- Use balm or rubs to relieve headache. Gently rub temples and back of neck.

- Rest in a quiet, dark room with no disturbance.

- Place a cold cloth over eyes and forehead.

- Avoid strong tea or coffee. Avoid items that trigger headaches.

- Take a paracetamol tablet if not improving with rubs.

- If not relieved with 4-5 doses of paracetamol, consult nurse or doctor.

- If frequent and severe headaches, fever, vomiting, altered consciousness, blurred vision or fits occur, contact the doctor immediately. 


\section{(iii) Diarrhea}

Diarrhea can occur with d4T, DDI, Kaletra, Crixivan, Ritonavir, Saquinavir and EFV. It is usually transient and passes over 2-4 weeks. Patients need to seek medical attention if diarrhea is accompanied by blood, mucus or fever, as this may be due to an intestinal infection requiring treatment. Patients would also need to seek medical advice if severe diarrhea occurs-more than 5 times per day, for 5 or more consecutive days, or results in weight loss of more than $5 \mathrm{lb}$.

The following advice can be given to the patient:

- Eat small meals more times a day.

- Eat soft easy to digest food-rice, bananas, biscuits. Avoid greasy, spicy and fatty foods.

- Drink sips of clean boiled water, weak tea, oral rehydration solution (ORS), lemon water. Avoid orange juice or very salty soups as they can increase diarrhea. Maintain hydration.

- If diarrhea is accompanied by fever, mucus or blood in stools, or is more than 4-5 times a day, contact the nurse or doctor.

\section{(iv) Rash}

Rashes are mostly seen with NVP, EFV and Abacavir. It is important to keep in mind that any new medication or ARV can also cause allergic rashes. Mild rash and itching can be treated with antihistaminic medications and calamine lotion. Severe hypersensitivity reactions with peeling of skin, watery discharge, blistering, and ulceration requires immediate physician referral and removing of offending medication as this can be a life threatening hypersensitivity reaction or Steven Johnson syndrome. The offending medication should not be restarted after such a strong reaction. With NVP, rash may accompany liver disturbances requiring a change of medication.

The patient can be given the following advice:

- Keep skin clean and dry.

- Use mild soaps—avoid scented and strong soaps.

- Drink plenty of water to keep skin hydrated and in good health.

- Avoid the sun when you have a rash.

- Doctors may prescribe benadryl, or other antihistaminic medications to relieve itching and rash.

- If rash is severe, associated with peeling of skin, blistering, ulceration or fever, contact the nurse or doctor immediately. You will need to change the medication. 


\section{(v) Neuropathy - numbness and tingling}

Numbness, tingling and burning of feet and hands is most commonly seen with d4T, DDI, ddC, 3TC, Ritonavir. Other ARV medications and INH, Rifampicin, can also cause neuropathy. Neuropathy with ARVs is usually progressive unless the offending medication is changed. Patients should report any symptoms to the nurse or physician. Neuropathy associated with INH or other medications may be reversed. Medications need to be changed quickly if associated with weakness and inability to walk. Symptoms can be relieved with vitamin supplements, and antidepressants such as amitryptaline prescribed by the physician.

The patient can be given the following advice:

- Protect your feet.

- Wear loose fitting shoes and socks.

- Keep feet uncovered in bed.

- Soakfeet in warm water; massage feet.

- Don't walk too much at a stretch.

- Ask doctor for pain relief medications, vitamin supplements.

- If no improvement, or difficulty in walking, contact nurse or physician.

\section{(vi) CNS symptoms}

Bad dreams, nightmares, headache, insomnia, depression, anxiety, difficulty in concentrating and dizziness are some symptoms seen with EFV. CNS symptoms pass over time. Taking medication at bedtime helps alleviate some of the symptoms. If symptoms do not improve or are associated with severe depression, suicidal ideation and withdrawal, the patient must consult a nurse or physician immediately. EFV may need to be replaced by another medication.

The patient can be given the following advice:

- Symptoms are usually temporary and pass in a few weeks.

- Take EFV at bedtime to minimize effects.

- Avoid a heavy meal before sleeping.

- Avoid alcohol and drugs.

- If you feel dizzy, sit down till the feeling goes away and try not to move quickly or lift anything heavy.

- Talk about your feelings with your friends or family.

- If youfeel very sad, or like crying all the time, or have thoughts of suicide, contact the nurse or doctor. 


\section{(vii) Fatigue}

Fatigue is a fairly common complaint and has multiple causes. HIV infection itself causes fatigue. Medications, depression, anemia can also cause fatigue. A change in lifestyle, maintaining a regular routine, adequate rest, and a balanced diet that includes vegetables and fruits, help to relieve fatigue. Patients should be advised to not consume alcohol and not to use recreational drugs.

The patient can be given the following advice:

- Avoid alcohol, tobacco and recreational drugs.

- Light physical exercise helps.

- Take a balanced diet that includes vegetables and fruits.

- Consult a doctor if you feel depressed, sad of have thoughts of suicide.

(viii) Lipoatrophy, lipodystropy and changes in physical appearance Patients who have been on treatment with $\mathrm{d} 4 \mathrm{~T}$, or protease inhibitors, for several months may notice changes in their physical appearance such as loss of fat from their cheeks, temples and limbs with increased redistribution of fat on the trunk. Lipoatrophy and lipodystrophy may be associated with metabolic changes such as changes in lipid profile and blood sugar levels. Patients should undergo routine check-ups by their physician. ARV medications may need to be changed and new medications to manage these side effects may be needed.

Hair loss is mostly seen with the use of Efavirenz. Hair loss is usually temporary. Patients can be advised to protect the hair from damage by not using hair-dyes and not braiding the hair. Patients should be discouraged from using commercially advertised products, as these are not helpful.

(ix) Side effects requiring laboratory diagnosis. Hepatitis, pancreatitis, anemia, renal dysfunction, lactic acidosis, metabolic disturbances like hyperlipidemia or hyperglycemia

These are side effects that are usually diagnosed through laboratory tests. Non-specific symptoms such as nausea, vomiting, diarrhea or pain in the abdomen may trigger the search for side effects such as lactic acidosis, pancreatitis, and hepatitis. For others such as hyperlipidemia or hyperglycemia, routine follow-up laboratory monitoring may detect abnormal values.

These side effects or adverse drug reactions (ADRs) are to be managed by the treating physician. Although nurse counselors may be able to identify these reactions based on laboratory reports, the treating physician should manage these events. Counselors should refer the patients to the physician at the earliest. 
The table below contains information for providers on 6 antiretroviral medications that are to be used in the ART program in Mombasa. These antiretroviral medications include commonly used first and second line medications recommended by WHO for use in developing country programs. Additional detailed information on other drugs is available online on the US Dept. of Health and Human Services website at http://www.aidsinfo.nih.gov/drugs/

\begin{tabular}{|c|c|c|}
\hline Name & Side effects & Action to be taken \\
\hline $\begin{array}{l}\text { D4T/ } \\
\text { Stavudine } \\
\text { Zerit }\end{array}$ & $\begin{array}{l}\text { Common: peripheral } \\
\text { neuropathy, headache, } \\
\text { rash, insomnia, nausea, } \\
\text { vomiting, diarrhea, } \\
\text { lipodystrophy } \\
\text { Rare: pancreatitis, } \\
\text { lactic acidosis-hepatic } \\
\text { steatosis (rare) }\end{array}$ & $\begin{array}{l}\text { 1. Inform the physician. } \\
\text { 2. Patients should report } \\
\text { severe abdominal pain, } \\
\text { vomiting. } \\
\text { 3. Peripheral neuropathy } \\
\text { requires symptomatic } \\
\text { treatment. } \\
\text { 4. Medication will need to } \\
\text { be changed if lactic } \\
\text { acidosis, pancreatitis or } \\
\text { severe neuropathy occur. }\end{array}$ \\
\hline $\begin{array}{l}3 \mathrm{TCl} \\
\text { Lamivudine/ } \\
\text { Epivir }\end{array}$ & $\begin{array}{l}\text { Common: dizziness, } \\
\text { headache, insomnia, } \\
\text { fatigue, nausea, rash } \\
\text { Rare: lactic acidosis-hepatic } \\
\text { steatosis (rare) }\end{array}$ & $\begin{array}{l}\text { 1. Inform the physician. } \\
\text { 2. Patients should report } \\
\text { severe abdominal pain, or } \\
\text { vomiting. If lactic acidosis, } \\
\text { medication will need to be } \\
\text { changed. }\end{array}$ \\
\hline $\begin{array}{l}\text { DDI/ } \\
\text { Didanosine/ } \\
\text { Videx }\end{array}$ & $\begin{array}{l}\text { Common: anxiety, headache, } \\
\text { insomnia, diarrhea, nausea } \\
\text { Rare: pancreatitis, peripheral } \\
\text { neuropathy, lactic acidosis- } \\
\text { hepatic steatosis }\end{array}$ & $\begin{array}{l}\text { 1. Inform the physician. } \\
\text { 2. Patients should report } \\
\text { severe abdominal pain, } \\
\text { vomiting. } \\
\text { 3. Nausea and diarrhea } \\
\text { disappear over } 2-4 \text { weeks. } \\
\text { 4. Peripheral neuropathy } \\
\text { needs symptomatic } \\
\text { treatment. } \\
\text { 5. Medication will need to } \\
\text { be changed if lactic } \\
\text { acidosis and pancreatitis } \\
\text { occur. }\end{array}$ \\
\hline
\end{tabular}

(Contd.) 
Table contd.

\begin{tabular}{|c|c|c|}
\hline Name & Side effects & Action to be taken \\
\hline $\begin{array}{l}\text { AZT/ } \\
\text { Retrovir/ } \\
\text { Zidovudine }\end{array}$ & $\begin{array}{l}\text { Common: nausea, anorexia, } \\
\text { headache, malaise, asthenia } \\
\text { Rare: bone marrow } \\
\text { suppression: anemia and or } \\
\text { neutropenia, lactic acidosis } \\
\text { with hepatic steatosis, } \\
\text { myopathy }\end{array}$ & $\begin{array}{l}\text { 1. Inform the physician. } \\
\text { 2. Nausea and diarrhea } \\
\text { disappear over } 2-4 \text { weeks. } \\
\text { 3. Patients should report } \\
\text { severe abdominal pain, } \\
\text { vomiting. Medication will } \\
\text { need to be changed if } \\
\text { lactic acidosis occurs. }\end{array}$ \\
\hline $\begin{array}{l}\text { Efavirenz/ } \\
\text { Sustiva }\end{array}$ & $\begin{array}{l}\text { Common: Rash, central } \\
\text { nervous system symptoms, } \\
\text { nausea, vomiting, anorexia, } \\
\text { diarrhea } \\
\text { Rare: severe rash, liver } \\
\text { toxicity and hepatitis, severe } \\
\text { depression with suicidal } \\
\text { ideation }\end{array}$ & $\begin{array}{l}\text { 1. Inform the physician. } \\
\text { 2. Mild-to-moderate rash } \\
\text { may disappear over } 4 \\
\text { weeks. } \\
\text { EFV to be discontinued in } \\
\text { case of severe rash } \\
\text { (blistering, desquamation). } \\
\text { 3. May consider changing } \\
\text { treatment in presence of } \\
\text { liver toxicity (enzymes } \\
\text { greater than } 5 \text { times } \\
\text { normal levels) or severe } \\
\text { rash. } \\
\text { 4. Central nervous system } \\
\text { (CNS) symptoms generally } \\
\text { relieved when EFV is } \\
\text { taken at bedtime. In case } \\
\text { of severe CNS symptoms } \\
\text { treatment may need to be } \\
\text { changed. }\end{array}$ \\
\hline
\end{tabular}

(Contd.) 
Table contd.

\begin{tabular}{|c|c|c|}
\hline Name & Side effects & Action to be taken \\
\hline Nevirapine & $\begin{array}{l}\text { Common: headache } \\
\text { Rare: rash, liver toxicity, } \\
\text { hepatitis, lipodystrophy }\end{array}$ & $\begin{array}{l}\text { 1. Inform physician. } \\
\text { 2. Liver enzymes in excess } \\
\text { of } 5 \text { times the normal } \\
\text { levels may require change } \\
\text { of medication. } \\
\text { 3. Mild rash usually } \\
\text { disappears over time and } \\
\text { can be treated with } \\
\text { calamine lotion and anti- } \\
\text { histaminic medications. } \\
\text { Severe rash with blistering } \\
\text { and desquamation will } \\
\text { require change in } \\
\text { treatment. }\end{array}$ \\
\hline $\begin{array}{l}\text { Kaletra/ } \\
\text { Lopinavir + } \\
\text { Ritonavir }\end{array}$ & $\begin{array}{l}\text { Common: gastrointestinal } \\
\text { intolerance, nausea, } \\
\text { vomiting, diarrhea, asthenia, } \\
\text { rash } \\
\text { Rare: liver toxicity, } \\
\text { pancreatitis, hyperglycemia, } \\
\text { lipodystrophy and lipid } \\
\text { disorders }\end{array}$ & $\begin{array}{l}\text { 1. Inform physician. } \\
\text { 2. GI intolerance generally } \\
\text { disappears over time. } \\
\text { 3. Hyperglycemia may } \\
\text { require insulin or oral } \\
\text { hypoglycemic agents. } \\
\text { 4. Treatment may need to } \\
\text { be suspended in cases of } \\
\text { pancreatitis. } \\
\text { 5. Lipid abnormalities } \\
\text { require management. } \\
\text { 6. Continue treatment in } \\
\text { cases with lipodystrophy. } \\
\text { 7. Liver enzymes need } \\
\text { monitoring. }\end{array}$ \\
\hline
\end{tabular}




\section{Information Resources}

\section{FURTHER READING}

Altice, F.L., F. Mostashari, G.H. Friedland. Trust and acceptance of and adherence to antiretroviral therapy. J of Acquired Immune Deficiency Syndromes 2001, 28: 47-58.

Bangsberg, D.R., F.M. Hechts, M. Chesney et al. Comparing objective methods of adherence assessment: electronic medication monitoring and unannounced pill counts. AIDS Behaviour 2001; 5: 575-81.

Chesney, M.A. Factors affecting adherence to antiretroviral therapy. Clinical Infectious Disease 2000; 30 S171-S76.

Farmer, P., F. Leander, J.S. Mukherjee et al. Community-based approaches to HIV treatment in resource poor settings. Lancet 358 (2001): 404-9.

Fischl, Margaret, Directly Observed Therapy for HIV Therapy in Corrections: Ready or Not? CROI Abstract, 528, 2001.

Ickovics, J.R. and C.S. Meads. Adherence to HAART among patients with HIV: Breakthroughs and barriers. AIDS Care 2002, 14(3): 309-18.

Kaplan, Andrew H. University of North Carolina, Prisons research group. Presentation of findings on a DOT HAART study at the Workshop of the Forum for Collaborative HIV Research, April 2001, Washington DC. In publishing.

Liu, H., C. Golin, L. Miller, A. Kaplan. A comparison study of multiple measures of adherence to HIV protease inhibitors. Ann Intern Med 2001; 134: 968-77.

Max, B. and R. Scherer. Management of the adverse effects of antiretroviral therapy and medication adherence. Clinical Infectious Diseases 2000; 30: S96-S116.

Paterson, D.L., S. Swindells, J. Mohr, M. Brester et al. Adherence to protease inhibitor therapy and outcomes in patients with HIV infection. Annals of Internal Medicine $2000 \mathrm{Jul} 4$; 133(1): 21-30.

Promoting Adherence to HIV Antiretroviral therapy. A Best Practice Manual. AIDS Institute. New York Department of Health.

Singh, N., C. Squire, C. Sivek et al. Determinants of compliance with antiretroviral therapy in patients with human immunodeficiency virus: prospective assessment with implications for enhancing compliance. AIDS Care 1996, 8: 261-9.

Stenzel, M.S., M. McKenzie, J.A. Mitty, T.P. Flannigan. Enhancing adherence to HAART: Pilot program of modified directly observed therapy. AIDS Read 2001 Jun; 11(6): 317-9, 324-8. 


\section{INTERNET RESOURCES}

AIDS Education and Training Centres (AETC), The http://www.aids-ed.org

National AIDS Manual in collaboration with the British Association, The http://www.aidsmap.com

HIV/AIDS treatment information website http://www.hivatis.org

http://www.medscape.com

US Dept of Health and Human Services

http//www.aidsinfo.nih.gov/drugs 


\section{Glossary}

Acute HIV Syndrome: Acute HIV syndrome is an acute 'flu-like' clinical syndrome experienced by $50-70 \%$ individuals approximately $3-6$ weeks after primary infection. It is characterized by fever, pharyngitis, rash, body ache, joint pains etc.

Confidentiality: The right to keep personal information, including medical information, exclusive to oneself. In a health care service delivery site this implies an assurance that personal and medical information is not disclosed to unauthorized persons, processes or devices. Only the person concerned has the right to disclose or sanction disclosure of personal information, except in exceptional circumstances.

Dose response effect: Dose response effect refers to a casual relationship between an exposure and an outcome or a disease. As the dose of exposure increases, the risk of disease also increases. In the case of adherence to antiretroviral therapy, as non-adherence to treatment increases, viral load levels increase in the blood.

Encephalitis: Inflammation of the brain. It may be caused by a viral or bacterial infection or may be part of an allergic response to a systemic viral illness or vaccination.

Hepatitis: Inflammation of the liver. It may be caused by a viral, bacterial or amoebic infection or may be part of an allergic response to medications. It can also occur as an autoimmune condition.

Herpes zoster: An inflammation of the skin caused by a Varicella-zoster virus (also causes chicken pox) characterized by collections of small blisters. Also known as 'shingles'.

Hyperglycemia: Raised levels of glucose in the blood typically seen in diabetes mellitus. Hyperglycemia may be seen with the use of protease inhibitors.

Hyperlipidemia: Raised levels of one or more class of lipoproteins in the blood. Lipids include cholesterol (LDL and HDL) and triglycerides. Use of Protease Inhibitors and Stavudine may be associated with an increase in total cholesterol and plasma triglycerides.

Hypersensitivity reactions: An allergic disorder in which the body becomes hypersensitive to particular antigens, which provoke characteristic symptoms whenever they are subsequently encountered.

Gold standard: An established and reliable standard against which a comparison can be made.

Immune reactivation syndrome: A paradoxical worsening of pre-existing untreated opportunistic infections seen following the initiation of effective antiretroviral therapy. This reflects the immediate improvements in immune function that occur as levels of HIV RNA drop and the immunosuppressive effects of HIV infection are controlled. Immune reconstitution: restoration of the immune system. 
Immune suppression: Suppression of the immune system. This may be due to an autoimmune illness, HIV infection or use of immunosuppressive medications.

Lactic acidosis: A condition resulting from an increase in serum lactate levels. Most commonly seen with the class of nucleoside analog antiretroviral medications such as Stavudine (d4T), Zidovudine (AZT), Lamivudine (3TC), Abacavir etc.

Lipoatrophy: Loss of fatty tissue. Lipodystrophy: Any disturbance of fat metabolism or of the distribution of fat in the body. In HIV/AIDS, lipodystrophy involves the redistribution of fat from the face, extremities and buttocks to around the abdomen resulting in peripheral wasting and truncal obesity. This is most commonly seen with the use of Stavudine and protease inhibitors.

Lymphadenopathy: Enlargement of the lymph nodes. This may be due to an infection or a malignant process.

Lymphoma: A tumour of the lymph nodes or lymphoid tissue.

Maximal and durable suppression of the virus: Near total and long-term suppression of the virus to undetectable levels in the blood.

Meningitis: An inflammation of the meninges (connective tissue membranes that line the skull and the vertebral canal) due to infection by viruses or bacteria.

Metabolic dysfunction: Metabolism involves the breakdown of complex organic constituents of the body with liberation of energy, which is required for other processes. In HIV/AIDS metabolic dysfunction with the use of antiretroviral medications especially protease inhibitors relates to the disturbance of lipid and glucose metabolism.

Mucocutaneous lesions: Lesions involving the mucous membranes and skin.

Neuropathy: Disease of the peripheral nerves, usually causing weakness and numbness.

Opportunistic infections: Bacterial, viral or fungal infections that occur when the immune system is suppressed.

Oral hairy cell leukoplakia: A mixed floral infection of the mucosal epithelium, most often affecting the side of the tongue.

Oral thrush: Lesions in the oral cavity caused by a fungal infection (Candidiasis) commonly seen in HIV/AIDS.

Pancreatitis: Inflammation of the pancreatic gland.

Protease inhibitors: A class of antiretroviral medications that inhibit HIV protease enzyme. This class includes medications such as Ritonavir, Indinavir, Amprenavir, Saquinavir, and Nelfinavir.

Recreational drugs: Addictive and narcotic drugs such as marijuana, cocaine, opiates (heroin etc.).

Steven Johnson syndrome: Severe and serious allergic skin reaction with rash, fever and blistering requiring hospitalization and immediate withdrawal of the offending medication.

Suicidal ideation: Ideas or thoughts of committing suicide.

Toxoplasmosis: Disease of mammals due to a protozoan Toxoplasma gondii. In HIV/AIDS can present as an encephalitis or space-occupying lesion in the brain.

Viral resistance: The degree to which the virus remains unaffected by antiretroviral medications. This occurs when the virus is exposed to sub-optimal levels of antiretroviral medications. 